\title{
Forecasting and Maintenance Problem under Subcontracting Constraint with Transportation Delay
}

\author{
Zied Hajej $^{\mathrm{a}-}$, Nidhal Rezg ${ }^{\mathrm{a}-}$, Ali Gharbi ${ }^{\mathrm{b}-}$ \\ ${ }^{\text {a- }}$ Laboratoire de Génie Industriel et Production de Metz, Université de Lorraine, Metz, France \\ ${ }^{\mathrm{b}-}$ Département de la production automatisée, Ecole de Technologie Supérieure, Montréal, Canada
}

\begin{abstract}
In this paper, a forecasting problem of production and maintenance plan optimization for random demand and single machine $M_{1}$ on a finite horizon. The function rate of the machine $M_{1}$ is depending on the production rate for each period of the forecasting horizon. In order to satisfy the customer, a subcontracting assures the rest of the production through machine $M_{2}$ with transportation delay. An analytic formulation of the problem has been proposed using a sequentially computation of the optimal production plan for which an optimal preventive maintenance policy has been calculated based on minimal repair. Firstly, we find, the optimal production plans of principal and subcontracting machines, which minimizes the total production and inventory cost for the cases without and with returned products under service level and subcontracting transportation delay. Secondly, we determine a joint effective maintenance policy with the optimal production plan, which integrates the various constraints for the production rates, the transportation delay and the returned production deadline. Numerical results are presented to highlight the application of the developed approach and Sensitivity analysis shows the robustness of the model.
\end{abstract}

Keywords: production plan, maintenance policy, subcontractor, transportation delay, random demand and service level.

\section{INTRODUCTION}

Ameliorating the situation of an industry requires certainly reducing costs and maximizing the customer satisfaction. These two goals can be achieved with a good management and a good making decision. The importance of subcontracting has grown both from the economic and production point of view. The new manufacturing paradigm that emphasis outsourcing, cooperation, networking and agility is much discussed in the general level, but very little empirical research has been done on these issues.

Concerning subcontracting context, Amesse et al. (1) introduced the importance of subcontracting strategy in the industrial world for all domains. Subcontracting is element of collaboration logic, coordination and management between the manufacturing companies in order to meet customers in terms of quantity and delay. [Andersen. (2) and Bertrand et al. (4)].

Recently, more works, relating to production and maintenance coupling, have integrated a new constraints corresponding to subcontracting concept. Among different works which dealt with the model under subcontracting constraints are Dellagi et al. (7) and Dahane et al. (8). The work of Dellagi et al. (6) contributed in the development of the integrated maintenance policies while coupling the maintenance and the production under subcontracting constraint. In your industrial model, they assumed that the production is consisting only one machine. In order to satisfy the customer demand, it is necessary to collaborate with another subcontracting machine. The work of Dahane et al.(8) aims at determining maintenance policies considering subcontracting concept but in case of provider of subcontracting service. Thus, the optimal age of the preventive replacement and the optimal stock level, considering the coupling between production and maintenance was determined. We can note that the demand, in several works concerning the subcontracting approach, is assumed constant and known during an infinite horizon. The type of this problem has become more difficult in case of a random demand during a finite horizon. In this case, the variations of production rates are necessary to meet such demand.

Regarding the production/inventory problem without maintenance, Holt et al. (13) proposed a model which defines a quadratic cost minimization program and that by approximating the cost functions for hiring labour and lay-off, overtime, inventory and shortage by suitable quadratic functions. As a result, and considering some constraints, this model provides an optimal smoothing solution for aggregate inventory, production and workforce. In this context, Silva and Cezarino (16) analyzed a production-planning optimization problem by both imperfect information of decision inventory variables and computing the expected value of the cost.

Concerning the interdependent relationship between the production and the maintenance planning, several works have dealt with this topic. So, in literature, we can find different attempts to study the problematic of conflict in management decisions and the necessity of combining both of objectives in order to enhance the global benefits of the industry and mainly to minimize global costs. On the other hand, various researches were performed to treat the problem of joint production and maintenance optimization. In this context, Aghazzaf et al.(4) developed a models dealing with integrated maintenance which based on the aggregated production planning where decision variables related to preventive and corrective maintenance are used. Recently, Hajej et al. (9) dealt with combined production and maintenance plans for a manufacturing system satisfying a random demand over a finite horizon. In their model, they considered the influence of production on the degradation of machine and consequently in maintenance planning. 
In our study, we build on Hajej et al. (10) and Ayed et al. (3) models. The given manufacturing system cannot ensure the total demand over the horizon. It calls upon the subcontracting. Ayed et al. (3) dealt with a randomly failing manufacturing system $M_{1}$ which has to satisfy a random demand during a finite horizon given a required service level. To help meeting this demand, subcontracting is used through another production system $M_{2} . M_{1}$ operates with a variable production rate and its failure rate depends on both time and production rate. But, Ayed et al.(3) and Hajej's et al (9),(10),(11) have ignored several significant characteristic and terms of manufacturing systems in their works such as transportation terms of delay, quantity and subcontracting transport. Considering the transportation terms, many researches are treating the transportation delays such as the delivery delay between a manufacturing store and a purchase warehouse, and their impact on manufacturing system. In this case we can cite the work of Richard and Chen (14), they considered a multi-agent architecture of supply chain integration and proposed a heuristics and programming models for the planning of demand driven supply chains by dealing two types of bidding approaches (customizing and webbing). Recently, Turki et al. (15), basing on the works of hajej's et al (9),(12), studied a simple manufacturing model composed of one machine with a transported delay between the store of production (manufacturing store) and purchase warehouse of customer by treating the impact of the delivery time and withdrawal right on the production/maintenance planning and transported quantity per period between the manufacturing store and the warehouse in order to satisfy a random demand.

Motivated by our work in the Turki et al (15), we treat the transportation aspect in another context that we consider a more complex and real industrial system, composed by two machines (principal and subcontractor machines), by integrating the subcontractor aspect with their characteristic such as transportation delay. This study shows that it has a novelty and originality relative to this type of problem which considers the subcontractor transportation delay in production and maintenance optimization plan. Indeed, it has been shown that subcontractor machine used to help a guarantee the desired service level by distribution of production charge so that the principal machine is not used with maximum rate since its degradation rate is correlated with the production.

The objective of this paper is to determine the economical production planning, during the finite horizon, based on forecasting demand taking into account the transportation delay of subcontracting. The impact of transportation delay on optimal production planning will be studied thereafter. Secondly, our objective is to establish economical production plans of the principal and subcontractor machines taking into account the influence of the products returned in the production system. The last objective is to determine a joint effective maintenance policy with the optimal production plan, which integrates the various constraints for the production rates, the transportation delay and the returned production deadline

This remainder of this paper is organized as follows: Section II states the problem without returned products case, formulates a general stochastic production/inventory model and develops the policy and analytical expression of production/inventory considering the influence of the subcontracting transportation delay on the production plans of principal and subcontracting machines. Section III deals with the returned products case of the initial system and shows the influence of the withdrawal right in the production system. Section IV presents and develops the policy and analytical expression of maintenance considering the influence of the subcontracting transportation delay and products returned on the optimal maintenance strategy. Finally, the conclusion is given in Section V.

\section{PRODUCTION PROBLEM: WITHOUT RETUNED PRODUCTS CASE}

\section{II.1. Problem statement: Without retuned products case}

In this work, an optimal production planning based on the demand forecasting problem is formulated. We consider a problem of manufacturing system, which produces one part-type through a single operation in order to satisfy a random demand over a finite horizon $H$. Moreover, we assume that the fluctuation of the demand is a normal distribution with mean and variance given respectively by $\hat{d}$ and $\sigma_{d}$. In order to satisfy this random demand with a given inventory service level $\alpha$, and to avoid shortage due to the manufacturing system unavailability, the enterprise has to build a stock. That's why, it calls upon another production enterprise, called subcontractor. Hence the transportation delay of subcontractor, denoted by $\tau$, is considered between the subcontractor machine and the stock $S$. Indeed, the products outgoing from subcontractor are transported to the stock and take a transportation delay $\tau$ to arrive to the principal stock. We noted that we can call the subcontractor machine and then the main machine is not working with a maximal capacity in order to reduce the total production, inventory and maintenance cost. It uses the subcontractor machine to reduce the pressure on the principal machine and therefore reduce the number of failures and the maintenance cost.

The subcontractor's manufacturing system $M_{2}$ maintenance is out of control. The only information about its maintenance is the availability rate $\beta_{2}$. This assumption is realistic, since each equipment has its own function of failure and therefore its availability can be calculated using the theory of reliability. In practice, the availability is an interesting indicator that companies are always trying to improve.

The machine $M_{2}$ is characterized too by its maximal production rate $U_{2}^{\max }$ and its unit production $\operatorname{cost} C_{p r 2}$ with $C_{p r 2}>C_{p r 1}$. The industrial problem is illustrated in the figure 1. 
Our objective is to establish an economical production plan satisfying the random demand, according to the demand forecasting and taking into account the transportation delay of subcontractor. The aim is to minimize the sum of the production and inventory costs.

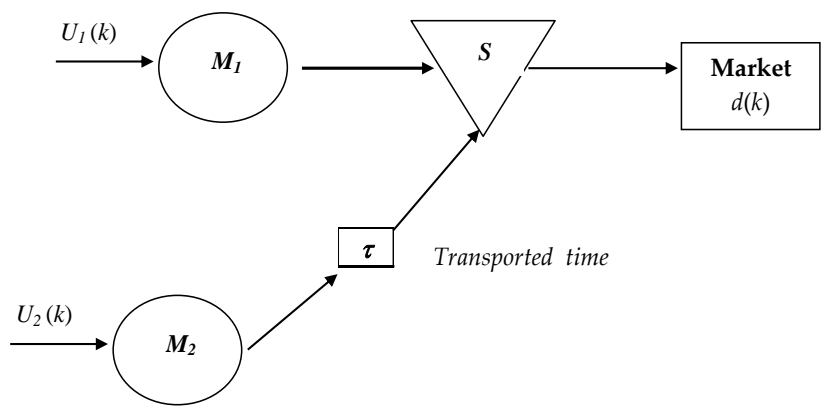

Fig.1. Problem description - Case without returned products

\section{II.2. Notation}

The following parameters are used in the mathematical formulation of the model:

$\tau:$ Transportation delay

$\tau$ ': returned production deadline

$\Delta t$ : length of a production period

$H$ : number of production periods in the planning horizon

$H . \Delta t$ : length of the finite planning horizon

$U_{i, k}$ : production rate by machine $M_{i}, i \in\{1,2\}$ during period $k(k=0,1, \ldots, H-1)$

$\hat{d}(k)$ : average demand during period $k(k=0,1, \ldots, H)$

$V_{d(k)}$ : variance of demand during period $k(k=0,1, \ldots, H)$

$S_{k}$ : inventory level of $S$ at the end of period $k(\mathrm{k}=0,1, \ldots, H)$

$\hat{S}_{k}$ : average inventory level of $S$ during period $k(k=0,1, \ldots, H)$

$C_{p r l}$ : unit production cost of machine $M_{l}$

$C_{p r 2}$ : unit production charged by the subcontractor $M_{2}$

$C s$ : holding cost of product unit during one period

mu: monetary unit

$U_{l}^{\text {max }}$ : maximal production rate of machine $M_{1}$

$U_{l}^{\text {min }}$ : minimal production rate of machine $M_{1}$

$U_{2}{ }^{\max }$ : maximal production rate of machine $M_{2}$

$U_{2}{ }^{\text {min }}$ : minimal production rate of machine $M_{2}$

$\alpha$ : probability index related to customer satisfaction and expressing the service level.

$\beta_{2}$ : machine $M_{2}$ availability rate

$\delta$ : percentage of returned products

$S_{0}$ : initial inventory.

$\xi_{M}$ : total maintenance cost

$C_{c m}$ : corrective maintenance cost

$C_{p m}$ : preventive maintenance cost

\section{II.3. Production Policy optimization}

The principal idea is to minimize the expected production and inventory costs over a finite time horizon [0, H]. It's supposed that the horizon is divided equally into $H$ periods Hajej et al. (9). The demand is satisfied at the end of each period. The problem can be formulated as a linear-stochastic optimal control problem under a stock threshold level constraint, with the production rates corresponding to each period as the decision variables.

The stochastic problem as follows: 
$f_{k}($.$) denotes functions that represent the production, and inventory costs, and E\{\}$ denote the mathematical average value operator. Referring to Hajej et al. (9), we formulate the problem as follows:

$$
\underset{U(k)}{\operatorname{Min}}\left(E\left\{\sum_{k=0}^{H-1} f_{k}\left(S_{k}, U_{k}\right)+f_{H}\left(S_{H}\right)\right\}\right)
$$

Subject to:

The inventory level of the inventory $S$ at the period $(k+1)$ that determine by inventory level of $S$ at the period $k$, production rate of principle machine $M$ during period $(k)$, production rate of subcontractor machine during period $(k-\tau)$ and demand rate during period $k$.

Consequently, the inventory balance equation for each time period is formulated in this way:

$$
S_{k+1}=S_{k}+U_{1, k}+\beta_{2} \cdot U_{2, k-\tau}-d_{k} \text { with } k \in\{0,1, \ldots, H-1\}
$$

With $\tau$ : transportation delay for the subcontractor.

The subcontractor products quantity that arrives to the stock $S$ at the period $k$ is the products quantity, which has left the subcontractor at the period $k$ - $\tau$. We can note that $\tau$ transportation delay according to production period length. i.e. after $\tau$ production periods, the products arrive, so we can write it as follows $\tau$. $\Delta t$ with $\tau \in\{1,2, \ldots \ldots\}$ and $\Delta t$ the length of production period. So writing $(k-\tau)$ is the period $k$ with $k \in\{1,2, \ldots \ldots\}$ minus $\tau$ to determine in which period the sub-contractor will begin delivery.

The service level constraint for each period is expressed by the following constraint.

$$
\operatorname{Prob}\left[S_{k+1} \geq 0\right] \geq \alpha \text { with } k \in\{0,1, \ldots, H-1\}
$$

The following constraint defines an upper and lower bounds on the production level during each period $k$.

$$
0 \leq U_{k} \leq U_{1}^{\max }+U_{2}^{\max } \text { with } k \in\{0,1, \ldots, H-1\} \quad U_{k}=U_{1, k}+\beta_{2} \cdot U_{2, k-\tau}
$$

\section{II.4. Total production and inventory cost}

In this section, we formulate a constrained stochastic problem under service level, subcontractor transportation delay and random demand by using the HMMS (Holt, Modigliani, Muth, Simon) model.

\section{a- HMMS model}

The HMMS model is considered one of the first models dealing the certainty-equivalence principle for dynamic linearquadratic problems Bertesekas et al. (6). It is usually applied as a benchmarking tool in order to compare different production planning approaches and to provide managers and decision makers with perspectives and ideas about how to manage the firm's material resources Singhal et al. (17). Some other works such as Hax et al. (12) proved that this quadratic approach (HMMS) is useful to evaluate the production process. So, for example, the quadratic inventory cost describes and takes into account both possible status of inventory: negative (rupture and backorders) and positive (overstocking).

Inspired by the HMMS model, we got the idea of making emphasis on the machines instead of workers, production rate and inventory levels in order to make the best and optimal production planning. Also, in our work, we make some changes on the model keeping its linear quadratic form. Furthermore, we take into account some constraints on the decision variables to make our approach more realistic and to ensure its applicability in real industrial cases.

\section{b- Quadratic total cost}

In our problem, we reformed this HMMS model to determine an inventory and production policy respecting the principle characteristic of HMMS model as the use of a quadratic cost function, which allows penalizing both excess and shortage in the inventory level.

The expected production and inventory cost for period $k$ is given by:

$$
f_{k}\left(U_{1, k}, U_{2, k}, S_{k}\right)=C_{s} E\left\{S_{k}^{2}\right\}+C_{p r 1} U_{1, k}^{2}+C_{p r 2} \beta_{2} U_{2, k}^{2}
$$


The total expected cost of production and inventory over the finite horizon $H . \Delta \mathrm{t}$ can then be expressed as follows:

$$
\begin{aligned}
& F(u)=\sum_{k=0}^{H} f_{k}\left(U_{1, k}, U_{2, k}, S_{k}\right)=C_{s} E\left\{S_{H}^{2}\right\}+\sum_{k=0}^{H-1}\left[C_{s} E\left\{S_{k}^{2}\right\}+C_{p r 1} U_{1, k}^{2}+C_{p r 2} \beta_{2} U_{2, k}^{2}\right] \\
& \text { with } k \in\{0,1, \ldots, H-1\}
\end{aligned}
$$

The choice of squared is justified to reflect the stock variation in storage and shortage using the mathematic expectation to 2 . To obtain a quadratic model both variables storage and production are squared. This is an approximation used by economists ( HMMS model).

\section{II.5. Analytical Study}

In this section, we would like to show the transformation of stochastic problem by the analytical study of policy and establish the deterministic equivalent problem.

\section{a- Production, inventory costs}

This approach consist the transformation of the stochastic problem into a deterministic equivalent by maintaining the principal properties of the original problem.

Firstly, we propose the following notation:

Mean variables:

$$
E\left\{S_{k}\right\}=\hat{S}_{k}, E\left\{U_{1, k}\right\}=U_{1, k}, E\left\{U_{2, k}\right\}=U_{2, k}
$$

$U_{k}$ being deterministic for each interval $\Delta t$, since it does not dependant on the random variables $d_{k}$ and $\hat{S}_{k}$.

Thus $\hat{U}_{k}=U_{k}$ and $\operatorname{Var}_{U_{k}}=0$ with $U_{k}=U_{1, k}+\beta \cdot U_{2, k-\tau}$

- The total production and inventory cost as follows:

\section{Lemma1:}

$$
F(u)=C_{s} \hat{S}_{H}^{2}+\sum_{k=0}^{H-1}\left[C_{s} \hat{S}_{k}^{2}+C_{p r 1} U_{1, k}^{2}+C_{p r 2} \beta_{2} U_{2, k}^{2}\right]+C_{s} \cdot \sigma_{d}^{2} \cdot \frac{H(H+1)}{2}
$$

Proof: see Annex

- The inventory balance equation:

$$
\hat{S}_{k+1}=\hat{S}_{k}+U_{1, k}+\beta_{2} \cdot U_{2, k-\tau}-\hat{d}_{k} \text { with } k \in\{0,1, \ldots, H-1\}
$$

b- The service level constraint:

To continue transforming the stochastic problem into an equivalent deterministic one, we consider a service level constraint in a deterministic form by specifying through the following lemma a minimum cumulative production quantity depending on the service level requirements.

\section{Lemma 2}

We recall that $\alpha$ defines the service level constraint. This constraint is expressed as follows:

$\operatorname{Prob}\left[S_{k+1} \geq 0\right] \geq \alpha$ with $0 \leq U_{k} \leq U_{1}^{\max }+U_{2}^{\max }$

Then, for $k=0,1, . ., H-1$ we have:

$U_{k} \geq U_{\alpha}\left(S_{k}, \alpha\right)$ with $U_{k}=U_{1, k}+\beta_{2} \cdot U_{2, k-\tau}$ 
Where $U_{\alpha}()$ represents a minimum cumulative production quantity expressed as follows:

$U_{\alpha}\left(S_{k}, \alpha\right)=V_{d_{k}} \varphi_{d_{k}}^{-1}(\alpha)+\hat{d}_{k}-S_{k} ; k=0,1, \ldots, H-1$, with:

$V_{d_{k}}$ : Variance of demand $d$ at period $k$

$\varphi_{d_{k}}$ : Cumulative Gaussian distribution function with mean $\hat{d}_{k}$ and finite variance $V_{d_{k}} \geq 0$

$\varphi_{d_{k}}^{-1}:$ Inverse distribution function.

\section{Proof:}

$\operatorname{Prob}\left[S_{k+1} \geq 0\right] \geq \alpha$ with $0 \leq U_{k} \leq U_{1}^{\max }+U_{2}^{\max }$

$U_{k}=U_{1, k}+\beta_{2} \cdot U_{2, k-\tau}$

$\Rightarrow \operatorname{Prob}\left[S_{k}+U_{1, k}+\beta_{2} \cdot U_{2, k-\tau}-d_{k} \geq 0\right] \geq \alpha$

$\Rightarrow \operatorname{Prob}\left[S_{k}+U_{1, k}+\beta_{2} \cdot U_{2, k-\tau} \geq d_{k}\right] \geq \alpha$

$\Rightarrow \operatorname{Prob}\left[S_{k}+U_{1, k}+\beta_{2} \cdot U_{2, k-\tau}-\hat{d}_{k} \geq d_{k}-\hat{d}_{k}\right] \geq \alpha$

$\Rightarrow \operatorname{Prob}\left[\frac{S_{k}+U_{1, k}+\beta_{2} \cdot U_{2, k-\tau}-\hat{d}_{k}}{V_{d_{k}}} \geq \frac{d_{k}-\hat{d}_{k}}{V_{d_{k}}}\right] \geq \alpha$

This equation is in the form of $\operatorname{Prob}[Y \geq X] \geq \alpha$, with $X=\frac{d_{k}-\hat{d}_{k}}{V_{d_{k}}}$ being a Gaussian random variable representing the demand $d_{k}$, and $\varphi_{d_{k}}$ is a cumulative Gaussian distribution function of the form $F(Y) \geq \alpha$ such as:

$\varphi_{d_{k}}\left(\frac{S_{k}+U_{1, k}+\beta_{2} \cdot U_{2, k-\tau}-\hat{d}_{k}}{V_{d_{k}}}\right) \geq \alpha$

Since $\lim \varphi_{d_{k}}=0$ and $\lim \varphi_{d_{k}}=1$, the function $\varphi_{d_{k}}$ is strictly increasing, and we note that it is indefinitely differentiable. That's why we conclude that $\varphi_{d_{k}}$ is invertible.

Thus,

(9) $\rightarrow \frac{S_{k}+U_{1, k}+\beta_{2} \cdot U_{2, k-\tau}-\hat{d}_{k}}{V_{d_{k}}} \geq \varphi_{d_{k}}^{-1}(\alpha)$

$\Rightarrow S_{k}+U_{1, k}+\beta_{2} \cdot U_{2, k-\tau}-\hat{d}_{k} \geq \varphi_{d_{k}}^{-1}(\alpha) \cdot V_{d_{k}}$

$\Rightarrow U_{1, k}+\beta_{2} \cdot U_{2, k-\tau} \geq \varphi_{d_{k}}^{-1}(\alpha) V_{d_{k}}-S_{k}+\hat{d}_{k}$

It can consequently be concluded that $U_{\alpha}\left(S_{k}, \alpha\right)=V_{d_{k}} \varphi_{d_{k}}^{-1}(\alpha)+\hat{d}_{k}-S_{k}$ with $k=0,1, \ldots, H-1$.

Using the last lemma 1 and lemma 2, we resume the equivalent deterministic model as follows:

$F(u)=C_{s} \hat{S}_{H}^{2}+\sum_{k=0}^{H-1}\left[C_{s} \cdot \hat{S}_{k}^{2}+C_{p r 1} \cdot U_{1, k}^{2}+C_{p r 2} \cdot \beta_{2} \cdot U_{2, k}^{2}\right]+C_{s}\left(\sigma_{d}\right)^{2} \frac{H(H+1)}{2}$

Under constraints:

$\hat{S}_{k+1}=\hat{S}_{k}+U_{1, k}+\beta_{2} \cdot U_{2, k-\tau}-d_{k}$ with $k=\{0,1, \ldots, H-1\}$

$U_{1, k}+\beta_{2} \cdot U_{2, k-\tau} \geq \varphi_{d_{k}}^{-1}(\theta) V_{d_{k}}-S_{k}+\hat{d}_{k}$ with $k=\{0,1, \ldots, H-1\}$ 
$\mathrm{O} \leq U_{k} \leq U_{1}^{\max }+U_{2}^{\max }$ with $k=\{0,1, \ldots, H-1\}$

$0 \leq U_{1, k} \leq U_{1}^{\max }$

$0 \leq U_{2, k} \leq U_{2}^{\max }$

$U_{k}=U_{1, k}+\beta_{2} \cdot U_{2, k-\tau}$

\section{II.6. Numerical Example}

In order to illustrate the model developed previously, we consider a company represented by machine $M_{l}$ which has to satisfy a stochastic demand assumed Gaussian over a finite horizon $H . \Delta t$; with a mean $\hat{d}_{k}$ and a variance $V_{d_{k}}$. The number $H$ of periods $\Delta t$ is equal to 24 , with $\Delta t=1$. To satisfy the demand with a given service level $\alpha$, the company resorts to a subcontractor represented by a machine $M_{2}$. The only information known about $M_{2}$ is the availability rate $\beta_{2}$. The following data are used for the other parameters: $C_{p r l}=3 m u, C_{p r 2}=10 m u, U_{1}^{m a U}=13, U_{2}^{m a U}=13, \beta_{2}=0.93$, service level $\alpha=0.95, C s=5 m u$, initial inventory $S_{0}=20$ and the variance of demand $V_{d_{k}}=1.21$. The average demand is presented in table 1 below.

\section{TABLE 1}

- Mean demand

\begin{tabular}{|c|c|c|c|c|c|c|c|}
\hline $\mathrm{d}_{0} \rightarrow 15$ & $\mathrm{~d}_{1} \rightarrow 17$ & $\mathrm{~d}_{2} \rightarrow 15$ & $\mathrm{~d}_{3} \rightarrow 15$ & $\mathrm{~d}_{4} \rightarrow 15$ & $d_{5} \rightarrow 14$ & $d_{6} \rightarrow 16$ & $d_{7} \rightarrow 14$ \\
\hline $\mathrm{d}_{8} \rightarrow 16$ & $\mathbf{d}_{9} \rightarrow 13$ & $\mathrm{~d}_{10} \rightarrow 15$ & $\mathrm{~d}_{11} \rightarrow 14$ & $\mathrm{~d}_{12} \rightarrow 15$ & $\mathrm{~d}_{13} \rightarrow 12$ & $\mathrm{~d}_{14} \rightarrow 15$ & $\mathrm{~d}_{15} \rightarrow 13$ \\
\hline $\mathrm{d}_{16} \rightarrow 15$ & $\mathrm{~d}_{17} \rightarrow 11$ & $\mathrm{~d}_{18} \rightarrow 16$ & $\mathrm{~d}_{19} \rightarrow 13$ & $\mathrm{~d}_{20} \rightarrow 15$ & $\mathrm{~d}_{21} \rightarrow 12$ & $\mathrm{~d}_{22} \rightarrow 14$ & $\mathrm{~d}_{23} \rightarrow 16$ \\
\hline
\end{tabular}

We used the Numerical Algorithms for Constrained Global Optimization (Nelder Mead methods) with MATHEMATICA, in order to realize this optimization. The economically production plan and the variability study are presented respectively in tables $2,3,4,5$ and figures $2,3,4$.

The above tables 2-5 illustrate an example result for an optimal production plans of principal and subcontracting machines which minimize the total cost for different values of the subcontracting transportation delay $\tau(\tau=0, \tau=1)$.

- $\tau=0$, cost $^{*}=25806.2$

\section{TABLE 2}

\begin{tabular}{|c|c|c|c|c|c|c|c|}
\hline \multicolumn{6}{|c|}{ Principal machine : $U^{*}{ }_{1, \mathrm{k}}$} \\
\hline $\mathrm{U}_{0} \rightarrow \mathbf{6}$ & $\mathrm{U}_{1} \rightarrow \mathbf{4}$ & $\mathrm{U}_{2} \rightarrow 7$ & $\mathrm{U}_{3} \rightarrow 6$ & $\mathrm{U}_{4} \rightarrow 9$ & $\mathrm{U}_{5} \rightarrow 3$ & $\mathrm{U}_{6} \rightarrow 6$ & $\mathrm{U}_{7} \rightarrow 10$ \\
\hline $\mathrm{U}_{8} \rightarrow \mathbf{4}$ & $\mathrm{U}_{9} \rightarrow 7$ & $\mathrm{U}_{10} \rightarrow 7$ & $\mathrm{U}_{11} \rightarrow 10$ & $\mathrm{U}_{12} \rightarrow 5$ & $\mathrm{U}_{13} \rightarrow 9$ & $\mathrm{U}_{14} \rightarrow 3$ & $\mathrm{U}_{15} \rightarrow 4$ \\
\hline $\mathrm{U}_{16} \rightarrow 6$ & $\mathrm{U}_{17} \rightarrow 3$ & $\mathrm{U}_{18} \rightarrow 10$ & $\mathrm{U}_{19} \rightarrow 9$ & $\mathrm{U}_{20} \rightarrow 3$ & $\mathrm{U}_{21} \rightarrow 6$ & $\mathrm{U}_{22} \rightarrow 7$ & $\mathrm{U}_{23} \rightarrow 10$ \\
\hline
\end{tabular}

TABLE 3

- Subcontractor machine : $U_{2, \mathrm{k}}$

\begin{tabular}{|c|c|c|c|c|c|c|c|}
\hline $\mathrm{U}_{0} \rightarrow 7$ & $\mathrm{U}_{1} \rightarrow 6$ & $\mathrm{U}_{2} \rightarrow 11$ & $\mathrm{U}_{3} \rightarrow 3$ & $\mathrm{U}_{4} \rightarrow 10$ & $\mathrm{U}_{5} \rightarrow 11$ & $\mathrm{U}_{6} \rightarrow 9$ & $\mathrm{U}_{7} \rightarrow 9$ \\
\hline $\mathrm{U}_{8} \rightarrow 11$ & $\mathrm{U}_{9} \rightarrow 3$ & $\mathrm{U}_{10} \rightarrow 4$ & $\mathrm{U}_{11} \rightarrow 10$ & $\mathrm{U}_{12} \rightarrow 10$ & $\mathrm{U}_{13} \rightarrow 7$ & $\mathrm{U}_{14} \rightarrow 10$ & $\mathrm{U}_{15} \rightarrow 11$ \\
\hline $\mathrm{U}_{16} \rightarrow 10$ & $\mathrm{U}_{17} \rightarrow 10$ & $\mathrm{U}_{18} \rightarrow 6$ & $\mathrm{U}_{19} \rightarrow 5$ & $\mathrm{U}_{20} \rightarrow 9$ & $\mathrm{U}_{21} \rightarrow 3$ & $\mathrm{U}_{22} \rightarrow 5$ & $\mathrm{U}_{23} \rightarrow 4$ \\
\hline
\end{tabular}


- $\tau=1, \operatorname{cost}^{*}=27150.9$

TABLE 4

- Principal machine : $U^{*}{ }_{1, \mathrm{k}}$

\begin{tabular}{|c|c|c|c|c|c|c|c|}
\hline $\mathrm{U}_{0} \rightarrow 6$ & $\mathrm{U}_{1} \rightarrow 10$ & $\mathrm{U}_{2} \rightarrow 11$ & $\mathrm{U}_{3} \rightarrow 11$ & $\mathrm{U}_{4} \rightarrow 5$ & $\mathrm{U}_{5} \rightarrow 11$ & $\mathrm{U}_{6} \rightarrow 6$ & $\mathrm{U}_{7} \rightarrow 10$ \\
\hline $\mathrm{U}_{8} \rightarrow 5$ & $\mathrm{U}_{9} \rightarrow 3$ & $\mathrm{U}_{10} \rightarrow 9$ & $\mathrm{U}_{11} \rightarrow 8$ & $\mathrm{U}_{12} \rightarrow 4$ & $\mathrm{U}_{13} \rightarrow 3$ & $\mathrm{U}_{14} \rightarrow 11$ & $\mathrm{U}_{15} \rightarrow 8$ \\
\hline $\mathrm{U}_{16} \rightarrow 11$ & $\mathrm{U}_{17} \rightarrow \mathbf{4}$ & $\mathrm{U}_{18} \rightarrow 8$ & $\mathrm{U}_{19} \rightarrow 5$ & $\mathrm{U}_{20} \rightarrow 7$ & $\mathrm{U}_{21} \rightarrow 9$ & $\mathrm{U}_{22} \rightarrow 2$ & $\mathrm{U}_{23} \rightarrow 6$ \\
\hline
\end{tabular}

TABLE 5

- Subcontractor machine : $U^{*}{ }_{2, \mathrm{k}}$

\begin{tabular}{|c|c|c|c|c|c|c|c|}
\hline $\mathrm{U}_{0} \rightarrow \mathbf{1 0}$ & $\mathrm{U}_{1} \rightarrow 5$ & $\mathrm{U}_{2} \rightarrow \mathbf{7}$ & $\mathrm{U}_{3} \rightarrow 6$ & $\mathrm{U}_{4} \rightarrow 10$ & $\mathrm{U}_{5} \rightarrow \mathbf{4}$ & $\mathrm{U}_{6} \rightarrow 6$ & $\mathrm{U}_{7} \rightarrow 10$ \\
\hline $\mathrm{U}_{8} \rightarrow \mathbf{1 1}$ & $\mathrm{U}_{9} \rightarrow \mathbf{9}$ & $\mathrm{U}_{10} \rightarrow 3$ & $\mathrm{U}_{11} \rightarrow 10$ & $\mathrm{U}_{12} \rightarrow 11$ & $\mathrm{U}_{13} \rightarrow 9$ & $\mathrm{U}_{14} \rightarrow 11$ & $\mathrm{U}_{15} \rightarrow 9$ \\
\hline $\mathrm{U}_{16} \rightarrow \mathbf{4}$ & $\mathrm{U}_{17} \rightarrow 9$ & $\mathrm{U}_{18} \rightarrow \mathbf{9}$ & $\mathrm{U}_{19} \rightarrow 7$ & $\mathrm{U}_{20} \rightarrow \mathbf{4}$ & $\mathrm{U}_{21} \rightarrow \mathbf{2}$ & $\mathrm{U}_{22} \rightarrow 6$ & - \\
\hline
\end{tabular}

- Variability of transportation delay $\tau$

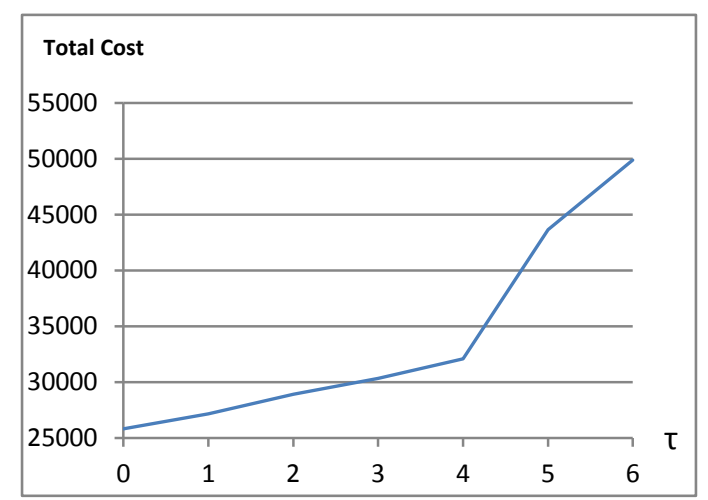

Fig.2. Total cost variation as a function of $\tau$
- Variability of service level $\alpha$

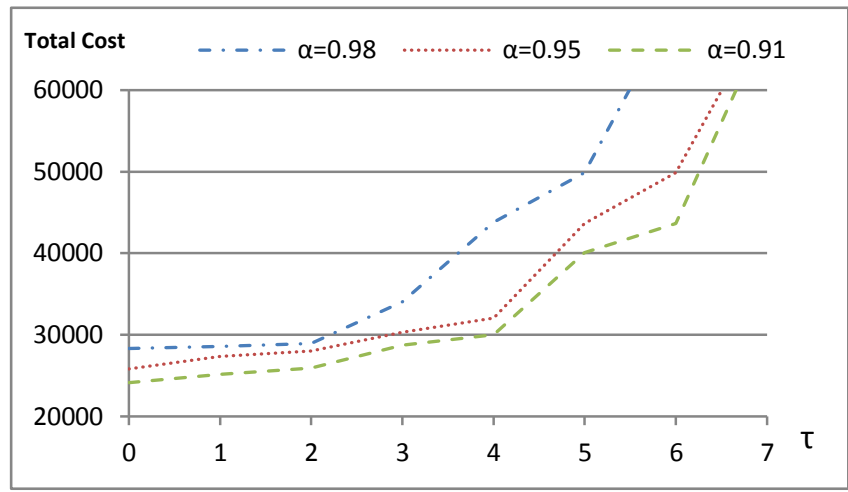

Fig.3. Total cost variation as a function of $\tau$ and service level $\alpha$ 
- Variability of transportation delay $\tau$

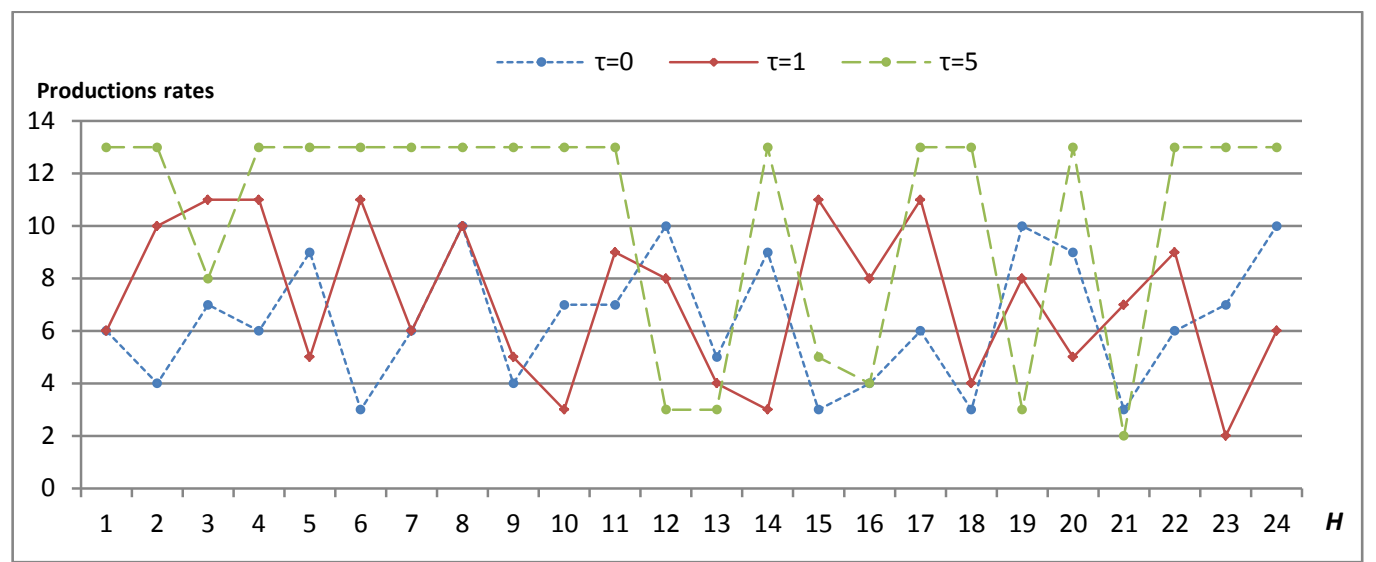

Fig.4. Production rates variation as a function of $\tau$

- Variability of demand variance $V_{d_{k}}$

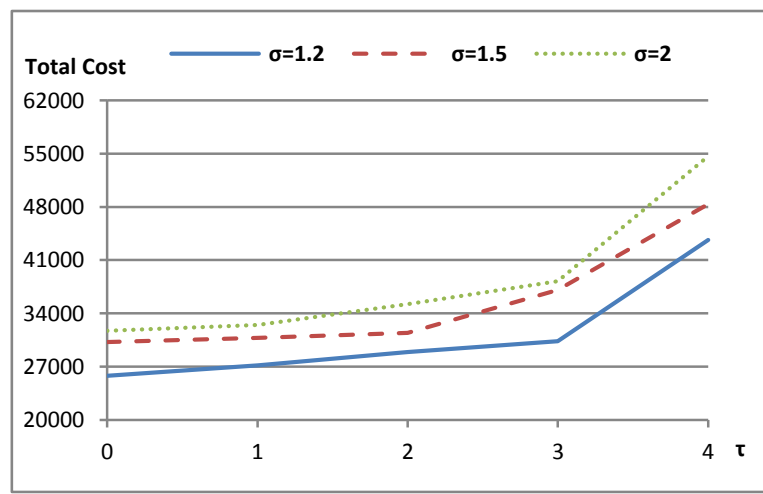

Fig.5. Total cost variation as a function of $\tau$ and demand variance $V_{d_{k}}$

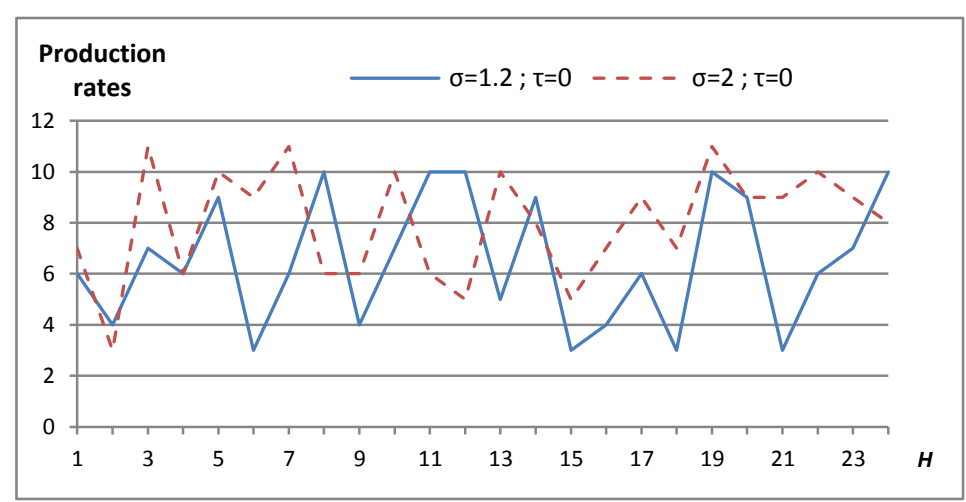

Fig.6. Production rates variation as a function of demand variance $V_{d_{k}}$

In what follows, we are interested to find the optimal production plans of principal and subcontracting machine for each value of transportation delay $\tau$. Using tables 2-5 and figure 2, we can see that the higher value of transportation delay $\tau$ corresponds to the higher of the optimal total cost. This can be explained by the fact that, as transportation delay $\tau$ increases, the production rates of principal machine increases in order to satisfy the service level that presented in Figure 4 . Similarly the stock level increases and therefore the optimal production/inventory total cost increases. On the Other hand, using figure 3, the higher value of the total production/inventory cost corresponds to the higher of the service level. We can note that, as service level $\alpha$ increases, the principal machine produces more and stores more to meet the demand and to satisfy the higher service level. Another point for production system behavior is that once the variance of demand increases, figure 5 shows that total production/inventory cost increases a function of the demand variance variability. This can be clarify by the reality that, as variance of demand increases, the production rates of principal and subcontractor machines increase (figure 6), the stock level augments and consequently the total production and inventory cost increases.

\section{PRODUCTION PROBLEM: WITH RETUNED PRODUCTS CASE}

\section{III.1. Problem statement: With returned products case}

In this section, we treat the returned products case of the initial system. In order to satisfy the random demand with inventory service level $\alpha$, the enterprise calls upon another subcontractor enterprise. In the same time, the production system takes into account the products returned by the customer who are still new and in stock. In the manufacturing field, the return of the 
products to stock, is called the withdrawal right. This right gives the customer a specific deadline $\tau$ ' for returning products. Our objective is to establish economical production plans of the principal and subcontractor machines taking into account the influence of the withdrawal right in the production system.

The problem is illustrated in Figure.7.

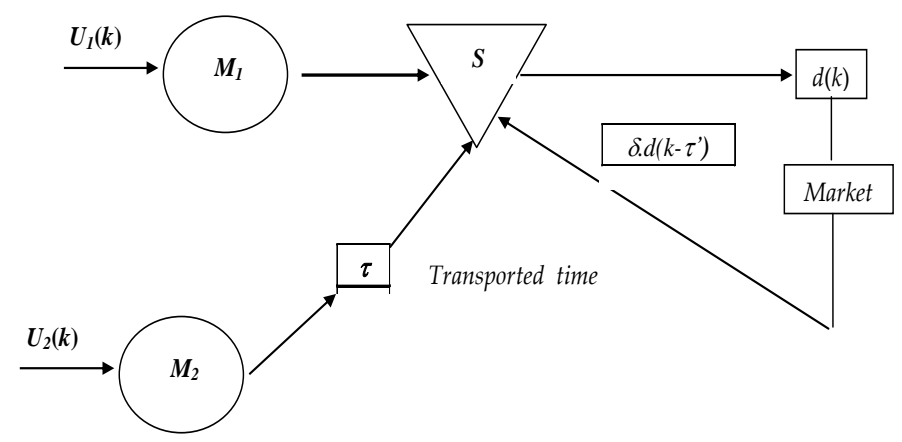

Fig.7. Problem description - Case with returned products

\section{III.2. Production Policy optimization}

The following stochastic problem provides an optimal production plans over the planning horizon:

$$
\underset{\left(U_{1}, U_{2}\right)}{\operatorname{Min}}\left(\sum_{k=0}^{H} f_{k}\left(U_{1, k}, U_{2, k}, S_{k}\right)=C_{s} \cdot E\left\{S_{H}^{2}\right\}+\sum_{k=0}^{H-1}\left[C_{s} \cdot E\left\{S_{k}^{2}\right\}+C_{p r 1} \cdot U_{1, k}^{2}+C_{p r 2} \cdot \beta_{2} \cdot U_{2, k}^{2}\right]\right)
$$

Subject to:

$$
\begin{aligned}
& S_{k+1}=S_{k}+U_{1, k}+\beta_{2} \cdot U_{2, k-\tau}+r(k)-d_{k} \text { with } k \in\{0,1, \ldots, H-1\} \\
& r(k)=\delta . d_{k-\tau}, \text { with } k \in\{0,1, \ldots, H-1\}
\end{aligned}
$$

$\operatorname{Prob}\left[S_{k+1} \geq 0\right] \geq \alpha$ with $k \in\{0,1, \ldots, H-1\}$

$$
0 \leq U_{k} \leq U_{1}^{\max }+U_{2}^{\max } \text { with } k \in\{0,1, \ldots, H-1\} \quad U_{k}=U_{1, k}+\beta_{2} \cdot U_{2, k-\tau}
$$

The same thing as the first section, Constraint (11) defines the inventory balance equation for each time period. The relation (12) defines the product quantity returned by the customer; this quantity is part of the demand returned by the customer after the specific deadline $\tau^{\prime}$. The constraint (13) imposes the service level requirement for each period as well as a lower bound on inventory variables so as to prevent stock outs. Finally, the last constraint defines an upper bound on the production level during each period $k$ cannot exceed a given maximal production rate.

\section{III.3. Analytical formulation}

In this section, we determine a deterministic formulation in order to easier the resolution of our stochastic problem.

a- Production and holding costs:

We can simplify the expected value of the production/inventory costs as follows: 


\section{Lemma3:}

$$
F\left(U_{1}, U_{2}\right)=C_{s} \cdot \hat{S}_{H}^{2}+\sum_{k=0}^{H-1}\left[C_{s} \cdot \hat{S}_{k}^{2}+C_{p r 1} \cdot U_{1, k}^{2}+C_{p r 2} \cdot \beta_{2} \cdot U_{2, k-\tau}^{2}\right]+C_{s} \cdot \sigma_{d}^{2} \cdot \frac{(H+1)}{2} \cdot\left[H+\delta^{2} \cdot(H-2)\right]
$$

b-The inventory balance equation:

Letting $d_{k}=\hat{d}_{k}$, the state balance equation of stock (eq.11) can be converted to:

$$
\begin{aligned}
& \hat{S}_{k+1}=\hat{S}_{k}+U_{1, k}+\beta_{2} \cdot U_{2, k-\tau}+\hat{r}_{k}-\hat{d}_{k} \text { with } k \in\{0,1, \ldots, H-1\} \\
& \hat{r}_{k}=\delta . \hat{d}_{k-\tau}, \text { with } k \in\{0,1, \ldots, H-1\}
\end{aligned}
$$

\section{Proof:}

It is assumed that the demand variable has its first and second statistic moments perfectly known for each period $k$, that is, $E\{d(k)\}=\hat{d}_{k}$ and $V_{d(k)}=\sigma_{d}^{2}$ for each $k$.

The inventory variables $S_{\mathrm{k}}$ is statistically described respectively by their means $E\left\{S_{k}\right\}=\hat{S}_{k}$ as well as their variance $V_{S_{k}}=E\left\{\left(S_{k}-\hat{S}_{k}\right)^{2}\right\}$

The inventory balance equation (2) can be reformulated as:

$$
\hat{S}_{k+1}=\hat{S}_{k}+U_{1, k}+\beta_{2} \cdot U_{2, k-\tau}+\delta . \hat{d}_{k-\tau^{\prime}}-\hat{d}_{k} \text { with } k \in\{0,1, \ldots, H-1\}
$$

- If we take the difference between equations (11) and (17) we obtain:

$$
\begin{aligned}
& S_{k+1}-\hat{S}_{k+1}=\left(S_{k}-\hat{S}_{k}\right)+(\underbrace{U_{1, k}-\hat{U}_{1, k}}_{0})+(\underbrace{\beta_{2} \cdot U_{2, k-\tau}-\beta_{2} \cdot \hat{U}_{2, k-\tau}}_{0})+\delta \cdot\left(d_{k-\tau_{1}}-\hat{d}_{k-\tau_{1}}\right)-\left(d_{k}-\hat{d}_{k}\right) \\
& \Rightarrow\left(S_{k+1}-\hat{S}_{k+1}\right)^{2}=\left(\left(S_{k}-\hat{S}_{k}\right)+\delta \cdot\left(d_{k-\tau_{1}}-\hat{d}_{k-\tau_{1}}\right)-\left(d_{k}-\hat{d}_{k}\right)\right)^{2} \\
& \Rightarrow E\left\{\left(S_{k+1}-\hat{S}_{k+1}\right)^{2}\right\}=E\left\{\left(S_{k}-\hat{S}_{k}\right)^{2}\right\}+E\left\{(\delta)^{2}\left(\left(d_{k-\tau_{1}}-\hat{d}_{k-\tau_{1}}\right)\right)^{2}\right\} \\
& +E\left\{\left(d_{k}-\hat{d}_{k}\right)^{2}\right\}+2 \cdot E\left\{\left(S_{k}-\hat{S}_{k}\right) \cdot \delta \cdot\left(d_{k-\tau_{1}}-\hat{d}_{k-\tau_{1}}\right)\right\} \\
& -2 \cdot E\left\{\left(S_{k}-\hat{S}_{k}\right) \cdot\left(d_{k}-\hat{d}_{k}\right)\right\}-2 \cdot E\left\{\left(d_{k}-\hat{d}_{k}\right) \cdot \delta \cdot\left(d_{k-\tau_{1}}-\hat{d}_{k-\tau_{1}}\right)\right\}
\end{aligned}
$$

Since $S_{k}$ and $d_{\mathrm{k}}$ are independent random variables, we can deduce that:

Hence:

$$
\begin{gathered}
E\left\{\left(S_{k}-\hat{S}_{k}\right) \cdot\left(d_{k}-\hat{d}_{k}\right)\right\}=E\left\{S_{k}-\hat{S}_{k}\right\} E\left\{d_{k}-\hat{d}_{k}\right\} \\
E\left\{\left(S_{k}-\hat{S}_{k}\right) \cdot \delta \cdot\left(d_{k-\tau_{1}}-\hat{d}_{k-\tau_{1}}\right)\right\}=\delta \cdot E\left\{S_{k}-\hat{S}_{k}\right\} \cdot E\left\{d_{k-\tau_{1}}-\hat{d}_{k-\tau_{1}}\right\} \\
E\left\{\left(d_{k}-\hat{d}_{k}\right) \cdot \delta \cdot\left(d_{k-\tau_{1}}-\hat{d}_{k-\tau_{1}}\right)\right\}=\delta \cdot E\left\{d_{k}-\hat{d}_{k}\right\} \cdot E\left\{d_{k-\tau_{1}}-\hat{d}_{k-\tau_{1}}\right\}
\end{gathered}
$$

$$
\begin{aligned}
& E\left\{S_{k}-\hat{S}_{k}\right\}=E\left\{S_{k}\right\}-E\left\{\hat{S}_{k}\right\}=0 \\
& E\left\{d_{k}-\hat{d}_{k}\right\}=E\left\{d_{k}\right\}-E\left\{\hat{d}_{k}\right\}=0
\end{aligned}
$$




$$
E\left\{d_{k-\tau_{1}}-\hat{d}_{k-\tau_{1}}\right\}=E\left\{d_{k-\tau_{1}}\right\}-E\left\{\hat{d}_{k-\tau_{1}}\right\}=0
$$

Therefore

$$
\Rightarrow E\left\{\left(S_{k+1}-\hat{S}_{k+1}\right)^{2}\right\}=E\left\{\left(S_{k}-\hat{S}_{k}\right)^{2}\right\}+(\delta)^{2} \cdot E\left\{\left(d_{k-\tau_{1}}-\hat{d}_{k-\tau_{1}}\right)^{2}\right\}+E\left\{\left(d_{k}-\hat{d}_{k}\right)^{2}\right\}
$$

If we assume that $V_{S}(k=0)=0$ and that $\sigma_{d_{k}}$ is constant and equal to $\sigma_{d}$ for all periods, we can deduce that

$V_{s}(k+1)=V_{s}(k)+\left((\delta)^{2}+1\right) \cdot \sigma_{d}^{2}$

For $k=0, V_{s}(1)=\sigma_{d}^{2}$,

$V_{s}(k)=\sigma_{d}^{2}\left(k+(k-1) \cdot(\delta)^{2}\right)$

Since $V_{S_{k}}=E\left\{\left(S_{k}-\hat{S}_{k}\right)^{2}\right\}=E\left\{S_{k}^{2}\right\}-\hat{S}_{k}^{2}$, we can write

$E\left\{S_{k}^{2}\right\}-\hat{S}_{k}^{2}=\sigma_{d}^{2}\left(k+(k-1) \cdot(\delta)^{2}\right)$

Hence,

$$
E\left\{S_{k}^{2}\right\}=\sigma_{d}^{2}\left(k+(k-1) \cdot(\delta)^{2}\right)+\hat{S}_{k}^{2}
$$

Substituting (18) in (6) we obtain:

$$
\begin{aligned}
& F\left(U_{1}, U_{2}\right)=\left(\sum_{k=0}^{H} f_{k}\left(U_{1, k}, U_{2, k}, S_{k}\right)=C_{s} \cdot E\left\{S_{H}^{2}\right\}+\sum_{k=0}^{H-1}\left[C_{s} \cdot E\left\{S_{k}^{2}\right\}+C_{p r 1} \cdot U_{1, k}^{2}+C_{p r 2} \cdot \beta_{2} \cdot U_{2, k-\tau}^{2}\right]\right) \\
& F\left(U_{1}, U_{2}\right)=\sum_{k=0}^{H} C_{s} \times\left[\hat{S}_{k}^{2}+\left(k+(k-1) \cdot(\delta)^{2}\right) \cdot \sigma_{d}^{2}\right]+\sum_{k=1}^{H-1}\left(C_{p r 1} \cdot U_{1, k}^{2}+C_{p r 2} \cdot \beta_{2} \cdot U_{2, k-\tau}^{2}\right) \\
& F\left(U_{1}, U_{2}\right)=\sum_{k=0}^{H} C_{s} \times \hat{S}_{k}^{2}+\sum_{k=0}^{H} C_{s} \times\left[\left(k+(k-1) \cdot \delta^{2}\right) \cdot \sigma_{d}^{2}\right]+\sum_{k=1}^{H-1}\left(C_{p r 1} \cdot U_{1, k}^{2}+C_{p r 2} \cdot \beta_{2} \cdot U_{2, k-\tau}^{2}\right) \\
& F\left(U_{1}, U_{2}\right)=C_{s} \times \hat{S}_{H}{ }^{2}+\sum_{k=1}^{H-1}\left(C_{s} \times \hat{S}_{k}^{2}+C_{p r 1} \cdot U_{1, k}^{2}+C_{p r 2} \cdot \beta_{2} \cdot U_{2, k-\tau}^{2}\right)+\sum_{k=0}^{H} C_{s} \times\left[\left(k+(k-1) \cdot \delta^{2}\right) \cdot \sigma_{d}^{2}\right] \\
& F\left(U_{1}, U_{2}\right)=C_{s} \times \hat{S}_{H}^{2}+\sum_{k=1}^{H-1}\left(C_{s} \times \hat{S}_{k}^{2}+C_{p r 1} \cdot U_{1, k}^{2}+C_{p r 2} \cdot \beta_{2} \cdot U_{2, k-\tau}^{2}\right)+C_{s} \cdot \sigma_{d}^{2} \cdot \sum_{k=0}^{H} k+C_{s} \cdot \delta^{2} \cdot \sigma_{d}^{2} \cdot \sum_{k=0}^{H}(k-1) \\
& F\left(U_{1}, U_{2}\right)=C_{s} \cdot \hat{S}_{H}^{2}+\sum_{k=0}^{H-1}\left[C_{s} \cdot \hat{S}_{k}^{2}+C_{p r 1} \cdot U_{1, k}^{2}+C_{p r 2} \cdot \beta_{2} \cdot U_{2, k-\tau}^{2}\right]+C_{s} \cdot \sigma_{d}^{2} \cdot \frac{(H+1)}{2} \cdot\left[H+\delta^{2} \cdot(H-2)\right]
\end{aligned}
$$

c-The service level constraint:

The transformation of the service level constraint in a deterministic form is given by the next lemma:

\section{Lemma 4:}

$\operatorname{Prob}\left[S_{k+1} \geq 0\right] \geq \alpha \Rightarrow U_{k} \geq U_{\alpha}\left(S_{k}, \alpha\right)$ with $U_{k}=U_{1, k}+\beta_{2} \cdot U_{2, k-\tau}$

With:

$U_{\alpha}\left(S_{k}, \alpha\right)$ : Minimum cumulative production quantity 


$$
U_{\theta}\left(S_{k}, \alpha\right)=\left(V_{d, k} \times V_{d, k-\tau^{\prime}}\right) \times \varphi^{-1}(\alpha)+\hat{d}_{k}-\delta \times \hat{d}_{k-\tau^{\prime}}-S_{k} \quad k=0,1, \ldots . ., H-1
$$

$V_{d, k}:$ Variance of demand $d$ at period $k$

$V_{d, k-\tau^{\prime}}$ : Variance of demand d at period $k-\tau$ '

$\varphi$ : Cumulative Gaussian distribution function with mean $\left(\frac{1}{V_{d, k-\tau^{\prime}}} \cdot \hat{d}_{k}-\frac{\delta}{V_{d, k}} \cdot \hat{d}_{k-\tau^{\prime}}\right)$ and finite variance

$\left(\left(\frac{1}{V_{d, k-\tau^{\prime}}}\right)^{2} \cdot V_{d, k}+\left(-\frac{\delta}{V_{d, k}}\right)^{2} \cdot V_{d, k-\tau^{\prime}} \geq 0\right)$

$\varphi^{-1}:$ Inverse distribution function

Proof:

$S_{k+1}=S_{k}+U_{1, k}+\beta_{2} \cdot U_{2, k-\tau}+r_{k}-d_{k}$

$\operatorname{Prob}\left(S_{k+1} \geq 0\right) \geq \alpha$

$\operatorname{Prob}\left(S_{k}+U_{1, k}+\beta_{2} \cdot U_{2, k-\tau}+r_{k}-d_{k} \geq 0\right) \geq \alpha$

$\operatorname{Pr} o b\left(S_{k}+U_{1, k}+\beta_{2} \cdot U_{2, k-\tau}+r_{k} \geq d_{k}\right) \geq \alpha$

$\operatorname{Prob}\left(S_{k}+U_{1, k}+\beta_{2} \cdot U_{2, k-\tau}+r_{k}-\hat{d}_{k} \geq d_{k}-\hat{d}_{k}\right) \geq \alpha$

$\operatorname{Prob}\left(d_{k}-\hat{d}_{k} \leq S_{k}+U_{1, k}+\beta_{2} \cdot U_{2, k-\tau}+r_{k}-\hat{d}_{k}\right) \geq \alpha$

$\operatorname{Pr} o b\left(d_{k}-\hat{d}_{k} \leq S_{k}+U_{1, k}+\beta_{2} \cdot U_{2, k-\tau}+\delta \cdot d_{k-\tau^{\prime}}-\hat{d}_{k}\right) \geq \alpha$

$$
\begin{gathered}
\operatorname{Prob}\left(d_{k}-\hat{d}_{k}-\delta \cdot d_{k-\tau^{\prime}}+\delta \cdot \hat{d}_{k-\tau^{\prime}} \leq S_{k}+U_{1, k}+\beta_{2} \cdot U_{2, k-\tau}+\delta \cdot \hat{d}_{k-\tau^{\prime}}-\hat{d}_{k}\right) \geq \alpha \\
\operatorname{Pr} o b\left(\frac{d_{k}-\hat{d}_{k}-\delta \cdot\left(d_{k-\tau^{\prime}}-\hat{d}_{k-\tau^{\prime}}\right)}{V_{d, k} \times V_{d, k-\tau^{\prime}}} \leq \frac{S_{k}+U_{1, k}+\beta_{2} \cdot U_{2, k-\tau}+\delta \cdot \hat{d}_{k-\tau^{\prime}}-\hat{d}_{k}}{V_{d, k} \times V_{d, k-\tau^{\prime}}}\right) \geq \alpha \\
\operatorname{Prob}\left(\frac{1}{V_{d, k-\tau^{\prime}}} \times \frac{d_{k}-\hat{d}_{k}}{V_{d, k}}-\frac{\delta}{V_{d, k}} \times \frac{d_{k-\tau^{\prime}}-\hat{d}_{k-\tau^{\prime}}}{V_{d, k-\tau^{\prime}}} \leq \frac{S_{k}+U_{1, k}+\beta_{2} \cdot U_{2, k-\tau}+\delta \cdot \hat{d}_{k-\tau^{\prime}}-\hat{d}_{k}}{V_{d, k} \times V_{d, k-\tau^{\prime}}}\right) \geq \alpha
\end{gathered}
$$

With

$\hat{d}_{k}:$ demand mean at period $k$

$\hat{d}_{k-\tau^{\prime}}:$ demand mean at period $\left(k-\tau^{\prime}\right)$

$\operatorname{Var}(d(k))=V_{d, k} \geq 0 \quad$ Variance of demand $d$ at period $k$

$\operatorname{Var}\left(d\left(k-\tau^{\prime}\right)\right)=V_{d, k-\tau^{\prime}} \geq 0$ Variance of demand $d$ at period $\left(k-\tau^{\prime}\right)$

Note that $X=\left(\frac{d_{k}-\hat{d}_{k}}{V_{d, k}}\right)$ : is a Gaussian random variable with an identical distribution as $d_{k}$.

and $Y=\left(\frac{d_{k-\tau^{\prime}}-\hat{d}_{k-\tau^{\prime}}}{V_{d, k-\tau^{\prime}}}\right):$ is a Gaussian random variable with an identical distribution as $d_{\mathrm{k}-\tau^{\prime}}$ 
This formulation is equivalent to $\operatorname{Prob}(A \times X+B \times Y \leq C) \geq \theta$ with $A=\frac{1}{V_{d, k-\tau^{\prime}}} \quad$ and $B=-\frac{\delta}{V_{d, k}}$ $X^{\prime}=A \times X$ is a Gaussian random variable with an identical distribution as $f_{x^{\prime}}=\frac{1}{A} \times f\left(\frac{y}{A}\right)$, with mean $A \cdot \hat{d}_{k}=\frac{1}{V_{d, k-\tau^{\prime}}} \cdot \hat{d}_{k}$ and variance $A^{2} \cdot V_{d, k}=\left(\frac{1}{V_{d, k-\tau^{\prime}}}\right)^{2} \cdot V_{d, k} \geq 0$

And $Y^{\prime}=B \times Y$ is a Gaussian random variable with an identical distribution as $f_{Y^{\prime}}=-\frac{1}{B} \times f\left(\frac{y}{B}\right)$, with mean $B \cdot \hat{d}_{k-\tau^{\prime}}=-\frac{\delta}{V_{d, k}} \cdot \hat{d}_{k-\tau^{\prime}}$ and variance $B^{2} \cdot V_{d, k-\tau^{\prime}}=\left(-\frac{\delta}{V_{d, k}}\right)^{2} \cdot V_{d, k-\tau^{\prime}} \geq 0$

Thus $T^{\prime}=X^{\prime}+Y^{\prime}$ is a Gaussian random variable with an identical distribution as $h=f_{x^{\prime}} * f_{y^{\prime}}$, with mean $A \cdot \hat{d}_{k}+B \cdot \hat{d}_{k-\tau^{\prime}}$ and variance $A^{2} \cdot V_{d, k}+B^{2} \cdot V_{d, k-\tau^{\prime}} \geq 0$

$\varphi$ : is a probability distribution function of $T^{\prime}$

$$
\varphi\left(\frac{S_{k}+U_{1, k}+\beta_{2} \cdot U_{2, k-\tau}+\delta \cdot \hat{d}_{k-\tau^{\prime}}-\hat{d}_{k}}{V_{d, k} \times V_{d, k-\tau^{\prime}}}\right) \geq \alpha
$$

Since $\lim _{+\infty} \varphi \rightarrow 0$ and $\lim _{+\infty} \varphi \rightarrow 1$ we conclude that $\varphi$ is strictly increasing. We note that $\varphi$ is indefinitely differentiable, so we conclude that $\varphi$ is invertible.

$$
\begin{gathered}
\frac{S_{k}+U_{1, k}+\beta_{2} \cdot U_{2, k-\tau}+\delta \cdot \hat{d}_{k-\tau^{\prime}}-\hat{d}_{k}}{V_{d, k} \times V_{d, k-\tau^{\prime}}} \geq \varphi^{-1}(\alpha) \\
U_{1, k}+\beta_{2} \cdot U_{2, k-\tau} \geq\left(V_{d, k} \times V_{d, k-\tau^{\prime}}\right) \times \varphi^{-1}(\alpha)+\hat{d}_{k}-\delta \times \hat{d}_{k-\tau^{\prime}}-S_{k}
\end{gathered}
$$

Thus

$$
\operatorname{Prob}\left(S_{k+1} \geq 0\right) \geq \alpha \Rightarrow\left(\left(U_{1, k}+\beta_{2} \cdot U_{2, k-\tau}\right) \geq\left(V_{d, k} \times V_{d, k-\tau^{\prime}}\right) \times \varphi^{-1}(\alpha)+\hat{d}_{k}-\delta \times \hat{d}_{k-\tau^{\prime}}-S_{k}\right) \quad k=0,1, \ldots . ., H-1
$$

\section{III.4. Numerical example}

In order to illustrate the model developed previously, we consider the same numerical example data of the previous section (Without retuned products case). We recall that production system is subject to the effects of seasonality seeks to develop a production plans of principal and subcontractor machine which minimizes total cost over a finite planning horizon $H=24$ periods each of $\Delta t=1$ month duration. The only information known about $M_{2}$ is its availability rate $\beta_{2}=0.93$. The values of the other parameters are as follows:

$C_{p r l}=3 m u, C_{p r 2}=10 m u, U_{1}^{\max }=13, U_{2}{ }^{\max }=13$, service level $\alpha=0.95, C_{s}=5 m u$, initial inventory $S_{0}=20$, the variance of demand $V_{d_{k}}=1.21$, percentage of backordered product $\delta \in[0,0.5]$ and returned production deadline $\tau^{\prime}=1$.

The average demand is presented in table 6 below. 
TABLE 6

- Mean demand

\begin{tabular}{|c|c|c|c|c|c|c|c|}
\hline$d_{0} \rightarrow 15$ & $d_{1} \rightarrow 17$ & $d_{2} \rightarrow 15$ & $d_{3} \rightarrow 15$ & $d_{4} \rightarrow 15$ & $d_{5} \rightarrow 14$ & $d_{6} \rightarrow 16$ & $d_{7} \rightarrow 14$ \\
\hline$d_{8} \rightarrow 16$ & $d_{9} \rightarrow 13$ & $d_{10} \rightarrow 15$ & $d_{11} \rightarrow 14$ & $d_{12} \rightarrow 15$ & $d_{13} \rightarrow 12$ & $d_{14} \rightarrow 15$ & $d_{15} \rightarrow 13$ \\
\hline$d_{16} \rightarrow 15$ & $d_{17} \rightarrow 11$ & $d_{18} \rightarrow 16$ & $d_{19} \rightarrow 13$ & $d_{20} \rightarrow 15$ & $d_{21} \rightarrow 12$ & $d_{22} \rightarrow 14$ & $d_{23} \rightarrow 16$ \\
\hline
\end{tabular}

- Variability of returned product percentage $\delta$

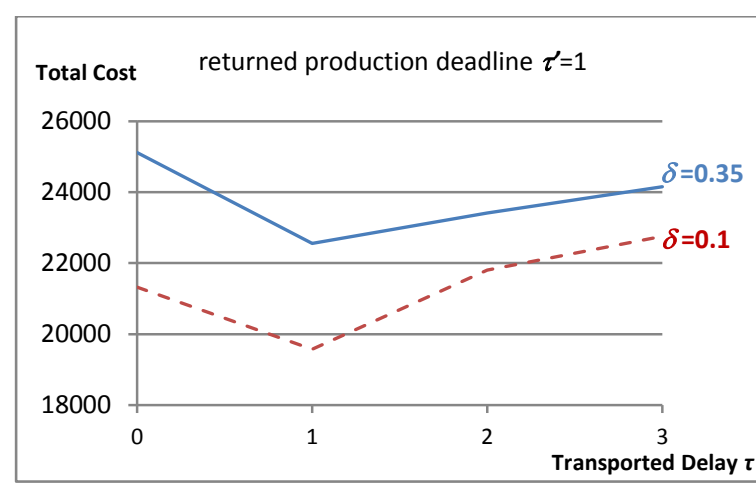

Fig.8. Total cost variation as a function of transportation delay $\tau$ and percentage products returned $\delta$

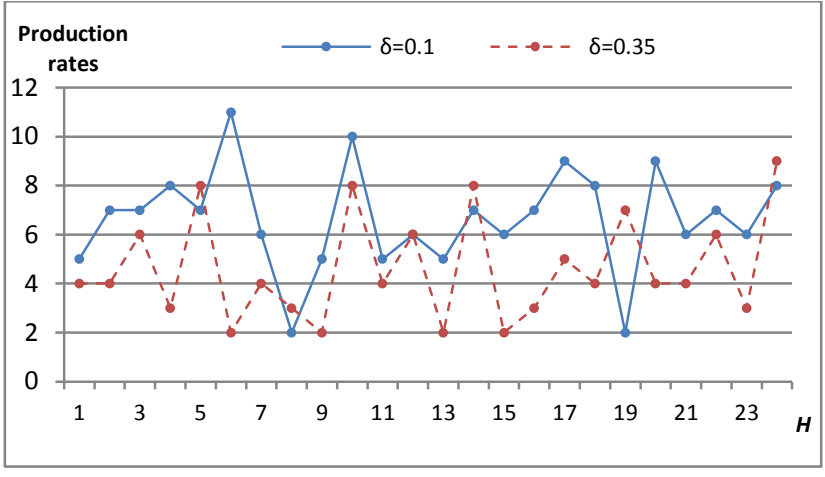

Fig.9. Production rates of principal machine variation as a function of percentage products returned $\delta$

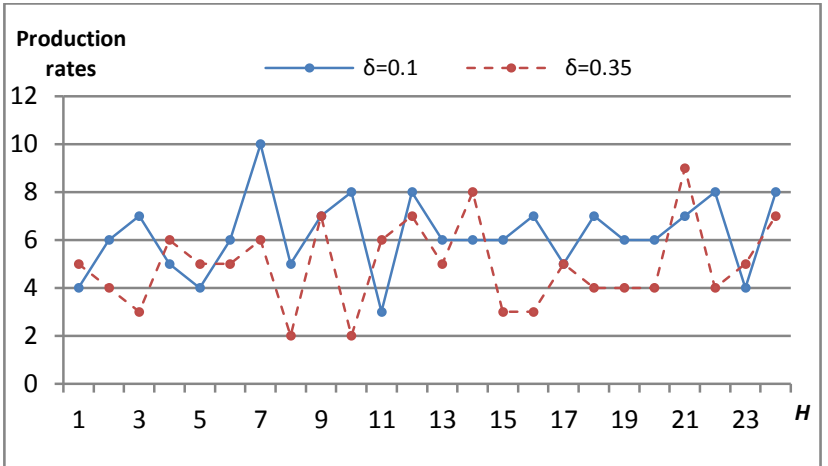

Fig.10. Production rates of subcontractor machine variation as a function of percentage products returned $\delta$

Figures 8-9-10 show the following results,

Hence, figure 8 shows that the higher value of $\delta$ (percentage of backordered product) corresponds to the lower of the optimal total cost. In the case where the transportation delay equals to backorder delay $\left(\tau=\tau^{\prime}=1\right)$, we obtained the best combination and the lower total cost. This can be explained by the fact that, as percentage products returned $\delta$ increases, the principal and the subcontractor machines produce less that presented in figures 9 and 10, because the returned product quantity will be in the principal stock to help satisfying the customer and to reduce the pressure on the principal and subcontractor machines. 


\section{III.5. Optimization of returned production deadline}

In this section, it's interesting to optimize the deadline authorized for the products return. The main idea is to express a relationship between the subcontractor transportation delay and the backorder delay. The relation as follows $\tau^{\prime}=\frac{\tau}{x}$ with $x \in] 0, \tau]$. The relationship takes into account the minimization of total production/inventory cost for a period of subcontractor transportation selected. This section will correlate the subcontractor transportation delay and the definition of the withdrawal period.

Our contribution is to show a relationship between transportation delay and the deadline for returned product. The relationship takes into account the minimization of total production/inventory cost for a period of subcontractor transportation selected. This relation correlates the subcontractor transported delay and the definition of the withdrawal period. The purpose of this relationship shows that we can find the best optimal combination of cost between the transportation delay and the deadline for returned product. This can be explained by the fact that, as the deadline for returned product decreases, the quantity of returned product to the principle stock increases in order to satisfy the customer and reduce the pressure on the principal and subcontractor machines and therefore decreases transportation delay of subcontractor. And in this case the subcontractor transported delay decreases and consequently the total production/inventory cost decreases. In the opposite case, if the deadline for returned product increases, the quantity of returned product decreases and consequently the principal machine will calls more the subcontracting and in this case the transportation delay of subcontractor decreases.

A small example will be presented to highlight the application of the optimization idea; we consider the same numerical example data of the previous section. We recall, that the objective is to determine the returned product deadline in order to minimize the total production/inventory cost for the subcontractor transportation delay $\tau=3$.

Case 1: Transportation Delay $\tau=3$, and $x=3$

- $\tau^{\prime}=1$ and $\operatorname{Cost}=22478.9 \mathrm{mu}$

\section{TABLE 7}

\begin{tabular}{|c|c|c|c|c|c|c|c|}
\hline $\mathrm{U}_{0} \rightarrow 7$ & $\mathrm{U}_{1} \rightarrow 10$ & $\mathrm{U}_{2} \rightarrow 8$ & $\mathrm{U}_{3} \rightarrow 5$ & $\mathrm{U}_{4} \rightarrow 6$ & $\mathrm{U}_{5} \rightarrow 3$ & $\mathrm{U}_{6} \rightarrow 4$ & $\mathrm{U}_{7} \rightarrow 5$ \\
\hline $\mathrm{U}_{8} \rightarrow 4$ & $\mathrm{U}_{9} \rightarrow 5$ & $\mathrm{U}_{10} \rightarrow \mathbf{2}$ & $\mathrm{U}_{11} \rightarrow 6$ & $\mathrm{U}_{12} \rightarrow 7$ & $\mathrm{U}_{13} \rightarrow 6$ & $\mathrm{U}_{14} \rightarrow 6$ & $\mathrm{U}_{15} \rightarrow 5$ \\
\hline $\mathrm{U}_{16} \rightarrow 6$ & $\mathrm{U}_{17} \rightarrow 6$ & $\mathrm{U}_{18} \rightarrow 5$ & $\mathrm{U}_{19} \rightarrow \mathbf{4}$ & $\mathrm{U}_{20} \rightarrow \mathbf{4}$ & $\mathrm{U}_{21} \rightarrow 5$ & $\mathrm{U}_{22} \rightarrow 8$ & $\mathrm{U}_{23} \rightarrow 6$ \\
\hline
\end{tabular}

\section{TABLE 8}

- Subcontractor machine: $U^{*}{ }_{2, \mathrm{k}}$

\begin{tabular}{|c|c|c|c|c|c|c|c|}
\hline $\mathrm{U}_{0} \rightarrow 7$ & $\mathrm{U}_{1} \rightarrow 6$ & $\mathrm{U}_{2} \rightarrow 8$ & $\mathrm{U}_{3} \rightarrow 7$ & $\mathrm{U}_{4} \rightarrow 5$ & $\mathrm{U}_{5} \rightarrow 5$ & $\mathrm{U}_{6} \rightarrow 4$ & $\mathrm{U}_{7} \rightarrow 5$ \\
\hline $\mathrm{U}_{8} \rightarrow 3$ & $\mathrm{U}_{9} \rightarrow \mathbf{4}$ & $\mathrm{U}_{10} \rightarrow 6$ & $\mathrm{U}_{11} \rightarrow 6$ & $\mathrm{U}_{12} \rightarrow 3$ & $\mathrm{U}_{13} \rightarrow 4$ & $\mathrm{U}_{14} \rightarrow 3$ & $\mathrm{U}_{15} \rightarrow \mathbf{2}$ \\
\hline $\mathrm{U}_{16} \rightarrow 9$ & $\mathrm{U}_{17} \rightarrow 6$ & $\mathrm{U}_{18} \rightarrow 7$ & $\mathrm{U}_{19} \rightarrow 8$ & $\mathrm{U}_{20} \rightarrow 6$ & - & - & - \\
\hline
\end{tabular}

Case 2: Transportation Delay $\tau=3$, and $x=1.5$

- $\tau^{\prime}=2$ and $\operatorname{Cost}^{*}=21155.1 \mathrm{mu}$ 


\section{TABLE 9}

- Principal machine : $U^{*}{ }_{1, \mathrm{k}}$

\begin{tabular}{|c|c|c|c|c|c|c|c|}
\hline $\mathrm{U}_{0} \rightarrow 9$ & $\mathrm{U}_{1} \rightarrow \mathbf{8}$ & $\mathrm{U}_{2} \rightarrow 10$ & $\mathrm{U}_{3} \rightarrow 7$ & $\mathrm{U}_{4} \rightarrow 8$ & $\mathrm{U}_{5} \rightarrow 5$ & $\mathrm{U}_{6} \rightarrow 2$ & $\mathrm{U}_{7} \rightarrow 7$ \\
\hline $\mathrm{U}_{8} \rightarrow 5$ & $\mathrm{U}_{9} \rightarrow 5$ & $\mathrm{U}_{10} \rightarrow 3$ & $\mathrm{U}_{11} \rightarrow 7$ & $\mathrm{U}_{12} \rightarrow 5$ & $\mathrm{U}_{13} \rightarrow 4$ & $\mathrm{U}_{14} \rightarrow 4$ & $\mathrm{U}_{15} \rightarrow 4$ \\
\hline $\mathrm{U}_{16} \rightarrow 7$ & $\mathrm{U}_{17} \rightarrow 5$ & $\mathrm{U}_{18} \rightarrow 3$ & $\mathrm{U}_{19} \rightarrow 5$ & $\mathrm{U}_{20} \rightarrow 4$ & $\mathrm{U}_{21} \rightarrow 8$ & $\mathrm{U}_{22} \rightarrow 7$ & $\mathrm{U}_{23} \rightarrow 2$ \\
\hline
\end{tabular}

TABLE 10

- Subcontractor machine : $U^{*}{ }_{2, \mathrm{k}}$

\begin{tabular}{|c|c|c|c|c|c|c|c|}
\hline $\mathrm{U}_{0} \rightarrow 6$ & $\mathrm{U}_{1} \rightarrow 5$ & $\mathrm{U}_{2} \rightarrow \mathbf{9}$ & $\mathrm{U}_{3} \rightarrow \mathbf{4}$ & $\mathrm{U}_{4} \rightarrow \mathbf{4}$ & $\mathrm{U}_{5} \rightarrow 6$ & $\mathrm{U}_{6} \rightarrow 5$ & $\mathrm{U}_{7} \rightarrow 2$ \\
\hline $\mathrm{U}_{8} \rightarrow \mathbf{4}$ & $\mathrm{U}_{9} \rightarrow \mathbf{4}$ & $\mathrm{U}_{10} \rightarrow \mathbf{4}$ & $\mathrm{U}_{11} \rightarrow 6$ & $\mathrm{U}_{12} \rightarrow 7$ & $\mathrm{U}_{13} \rightarrow 3$ & $\mathrm{U}_{14} \rightarrow 6$ & $\mathrm{U}_{15} \rightarrow 5$ \\
\hline $\mathrm{U}_{16} \rightarrow 7$ & $\mathrm{U}_{17} \rightarrow \mathbf{8}$ & $\mathrm{U}_{18} \rightarrow 6$ & $\mathrm{U}_{19} \rightarrow 5$ & $\mathrm{U}_{20} \rightarrow 7$ & - & - & - \\
\hline
\end{tabular}

Case 3: Transportation Delay $\tau=3$, and $x=1$

- $\quad \tau^{\prime}=3$ and $\operatorname{Cost}=24974.9 \mathrm{mu}$

TABLE 11

- Principal machine : $U^{*}{ }_{1, \mathrm{k}}$

\begin{tabular}{|c|c|c|c|c|c|c|c|}
\hline $\mathrm{U}_{0} \rightarrow 8$ & $\mathrm{U}_{1} \rightarrow 9$ & $\mathrm{U}_{2} \rightarrow 12$ & $\mathrm{U}_{3} \rightarrow 10$ & $\mathrm{U}_{4} \rightarrow 5$ & $\mathrm{U}_{5} \rightarrow 6$ & $\mathrm{U}_{6} \rightarrow 0$ & $\mathrm{U}_{7} \rightarrow 7$ \\
\hline $\mathrm{U}_{8} \rightarrow \mathbf{4}$ & $\mathrm{U}_{9} \rightarrow 7$ & $\mathrm{U}_{10} \rightarrow 3$ & $\mathrm{U}_{11} \rightarrow 6$ & $\mathrm{U}_{12} \rightarrow 4$ & $\mathrm{U}_{13} \rightarrow 4$ & $\mathrm{U}_{14} \rightarrow 4$ & $\mathrm{U}_{15} \rightarrow 4$ \\
\hline $\mathrm{U}_{16} \rightarrow \mathbf{8}$ & $\mathrm{U}_{17} \rightarrow 5$ & $\mathrm{U}_{18} \rightarrow 2$ & $\mathrm{U}_{19} \rightarrow 8$ & $\mathrm{U}_{20} \rightarrow 5$ & $\mathrm{U}_{21} \rightarrow 8$ & $\mathrm{U}_{22} \rightarrow 10$ & $\mathrm{U}_{23} \rightarrow 5$ \\
\hline
\end{tabular}

TABLE 12

- Subcontractor machine : $U^{*}{ }_{2, \mathrm{k}}$

\begin{tabular}{|c|c|c|c|c|c|c|c|}
\hline $\mathrm{U}_{0} \rightarrow 5$ & $\mathrm{U}_{1} \rightarrow 7$ & $\mathrm{U}_{2} \rightarrow 7$ & $\mathrm{U}_{3} \rightarrow 8$ & $\mathrm{U}_{4} \rightarrow 3$ & $\mathrm{U}_{5} \rightarrow 4$ & $\mathrm{U}_{6} \rightarrow 6$ & $\mathrm{U}_{7} \rightarrow 6$ \\
\hline $\mathrm{U}_{8} \rightarrow 8$ & $\mathrm{U}_{9} \rightarrow 8$ & $\mathrm{U}_{10} \rightarrow 1$ & $\mathrm{U}_{11} \rightarrow 1$ & $\mathrm{U}_{12} \rightarrow 7$ & $\mathrm{U}_{13} \rightarrow 7$ & $\mathrm{U}_{14} \rightarrow 1$ & $\mathrm{U}_{15} \rightarrow 8$ \\
\hline $\mathrm{U}_{16} \rightarrow 7$ & $\mathrm{U}_{17} \rightarrow \mathbf{4}$ & $\mathrm{U}_{18} \rightarrow 3$ & $\mathrm{U}_{19} \rightarrow 5$ & $\mathrm{U}_{20} \rightarrow 9$ & - & - & - \\
\hline
\end{tabular}




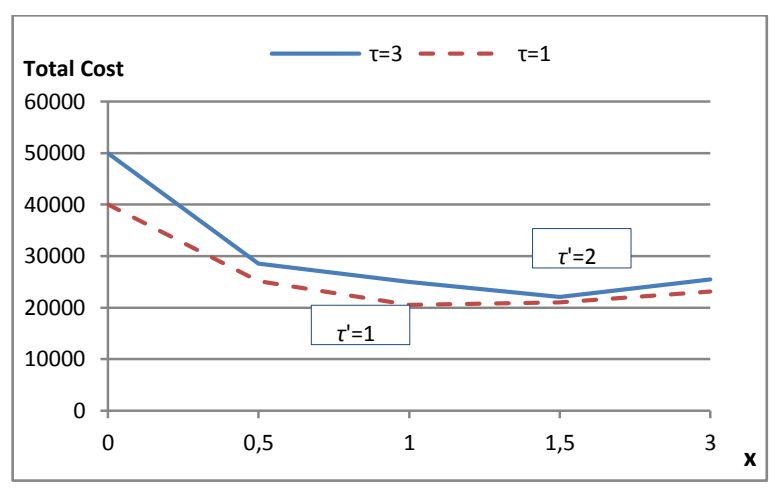

Fig.11. Variability of Returned production deadline

Tables 7-12 and Figures 11 show the following results: The above tables and figure illustrates the minimum total cost for different values of $x \in[1, \tau]$. For each value of $x$, we calculate the economical production plans of subcontractor and principal machines. Using figure 9, we note that for subcontractor transportation delay $\tau=1$, the optimal total cost is obtained for $x=1$ corresponding to optimal returned product deadline $\tau^{\prime}=1$ as for subcontractor transportation delay $\tau=3$ the withdrawal right requires that the optimal returned product deadline $\tau^{\prime}=2$.

Hence, based on the results of previous sections and this section, we can notice that when $\tau$ increases, we produce more on the principal machine and store more to meet the future periods. According to the previous results presented through the variability of $\tau$, the storage costs that are really impacted visibly. Thus, the desirable strategy to adopt for the return of products from customers is finding an optimal period (maximal delay of backorder) in order to remove pressure on the stock and to reduce costs, therefore the choice of $\tau^{\prime}$ must be optimized and correlated with the subcontractor transportation delay $\tau$. The results presented in Section III.5 shows the existence of an optimum.

\section{JOINT MAINTENANCE POLICY}

The aim of this section is to determine a joint effective maintenance policy with the plan of optimal plan of production which integrates the various constraints for the production rates, the transportation delay and the returned production deadline. The maintenance policy has to allow assuring at best the realization of the volumes necessary for the customer demand. We adopt a maintenance policy based on block strategy and joint to the forecast. This maintenance policy brings the reliability necessary for the main machine which has to undergo in a direct way the impact of delivery deadline as demonstrated previously. Its advantage is that it is easy to apply without it disrupts the plan of production. In this section, we precede to the optimization of this proposed policy in order to determine the optimal period on the horizon $H$ according to a criterion of cost minimization.

\section{IV.1. Problem Description}

The machine $M$ is subject to random failures, its probability degradation law being described by the probability density function of time to failure $f(t)$ for which the failure rate $\lambda(t)$ increases with both time and the production rate $U_{l}(t)$. A correlation is made between the influence of production rate variation on the equipment degradation and hence on the average number of failures. Thus, the contribution of maintenance is to improve the availability of machine reducing the maintenance costs in order to ensure the production plan on the horizon $H$. The maintenance strategy under consideration is the well-known preventive maintenance policy with minimal repair at failure. The novelty of this contribution compared to the literature is that in previous work, the authors developed the theory of Hedging Point with a production rate varies only between 0 and $d$ (request) or Umax (maximal rate). In our work, we calculate the production rates of each period in order to reflect the commitments of the planning while correlating the degradation of the machine production rates. We are in logic of production rate optimization over a finite horizon. As these production rates vary from one period to another, the maintenance plan must follow accordingly because the degradation is not uniform over the planning horizon. It is used to calculate the periodicities of preventive maintenance actions.

The horizon $H$ is partitioned equally into $N$ parts each of length $T$. Perfect preventive maintenance or replacement is performed periodically at times $i . T, i=0,1, \ldots, N$ and $N . T=H . \Delta t$ following which the unit is as good as new. When a unit fails between preventive maintenance actions, only minimal repair is performed. It is assumed that the repair and replacement times are negligible.

The dependence of the system degradation to production plan is manifested by an increased failure rate according to both time and the production rate Hajej et al.(10). That is why we focused on the joint optimization strategy in which we considered the maintenance strategy, to establish the optimal maintenance strategy according to a criterion of cost minimization 
characterized, characterized by the optimal number $N^{*}$ of preventive maintenance actions to perform over the finite horizon $H . \Delta t$.

\section{IV.2. Analytical Study}

The analytic expression of the total maintenance cost is as follows, where $N \in\{1,2,3 \ldots .$.$\} and A_{M}\left(U_{1}, N\right)$ corresponds to the expected number of failures that occur during the horizon $H$, considering the production rate in each production period $\Delta t$.

$\xi_{M}\left(U_{1}, N\right)=C_{p m} \times(N-1)+C_{c m} \times A_{M}\left(U_{1}, N\right)$

Each period $k$ of the horizon $H$ is characterized by its own production rate $U_{k}$ established from the production plan. The failure rate evolves in each interval according to the production rate adopted in this interval. It also depends on the failure rate cumulated at the end of the previous period. As per Hajej's et al (10) approach, the degradation in the end of the period is then accounted for. In fact, the failure rate in the interval $k$ is expressed as following:

$$
\lambda_{k, j}(t)=\lambda_{k-1, j}(\Delta t)+\frac{U_{k, j}}{U_{\max }} \lambda_{n}(t) \quad \forall t \in[0, \Delta t] \text { and } \forall j \in[0,1, \ldots, N]
$$

Where $\mathrm{j}$ presented the interval of maintenance actions

With $\lambda_{k, j=0}=\lambda_{0, j}$ and $\Delta \lambda_{k, j}(t)=\frac{U_{k, j}}{U_{\max }} \lambda_{n}(t)$

$\lambda_{n}(t)$ is the nominal failure rate corresponding to the maximal production rate.

We recall that Hajej's et al (10) assumed that machine degradation is linear according to the production rate.

We can write the failure rate function as expressed in the following way by Hajej's et al (10):

$$
\lambda_{k, j}(t)=\lambda_{0, j}+\sum_{l=1}^{k-1} \frac{U_{l, j}}{U_{\max }} \lambda_{n}(\Delta t)+\frac{U_{k, j}}{U_{\max }} \lambda_{n}(t) \text { with } t \in[0, \Delta t]
$$

Let $I n$ denote the integer part of (.). Then the average failure number over the horizon $H . \Delta \mathrm{t}$ is:

$$
\begin{aligned}
& A_{M}(U, N)=\sum_{j=0}^{N-1}\left[\sum_{i=\operatorname{In}\left(j \times \frac{T}{\Delta t}\right)+1} \int_{0}^{\operatorname{In}\left((j+1) \times \frac{T}{\Delta t}\right)} \lambda_{i, j}(t)+\int_{0}^{(j+1) \times T-\operatorname{In}\left((j+1) \times \frac{T}{\Delta t}\right) \times \Delta t} \lambda_{I n\left((j+1) \times \frac{T}{\Delta t}\right)+1, j}(t) d t\right. \\
& \left.+\quad \int_{0}^{\left(\ln \left((j+1) \times \frac{T}{\Delta t}\right)+1\right) \times \Delta t-(j+1) \times T} \frac{\left(u\left(\operatorname{In}\left((j+1) \times \frac{T}{\Delta t}\right)+1\right)\right)}{U_{\max }} \times \lambda_{n}(t) d t\right]
\end{aligned}
$$

Therefore, we replace $\lambda_{i}(t)$ in the expression (25): 


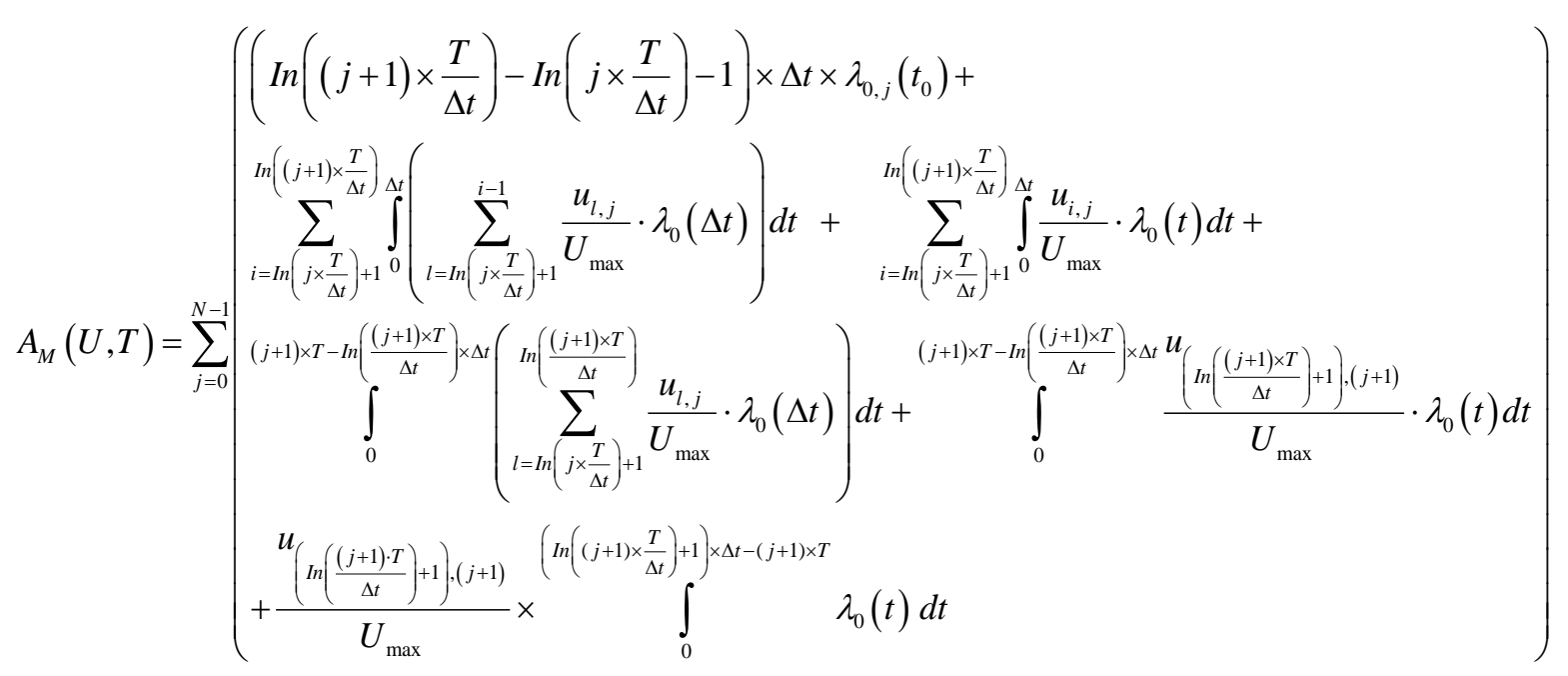

We now replace $T=H / N$ :

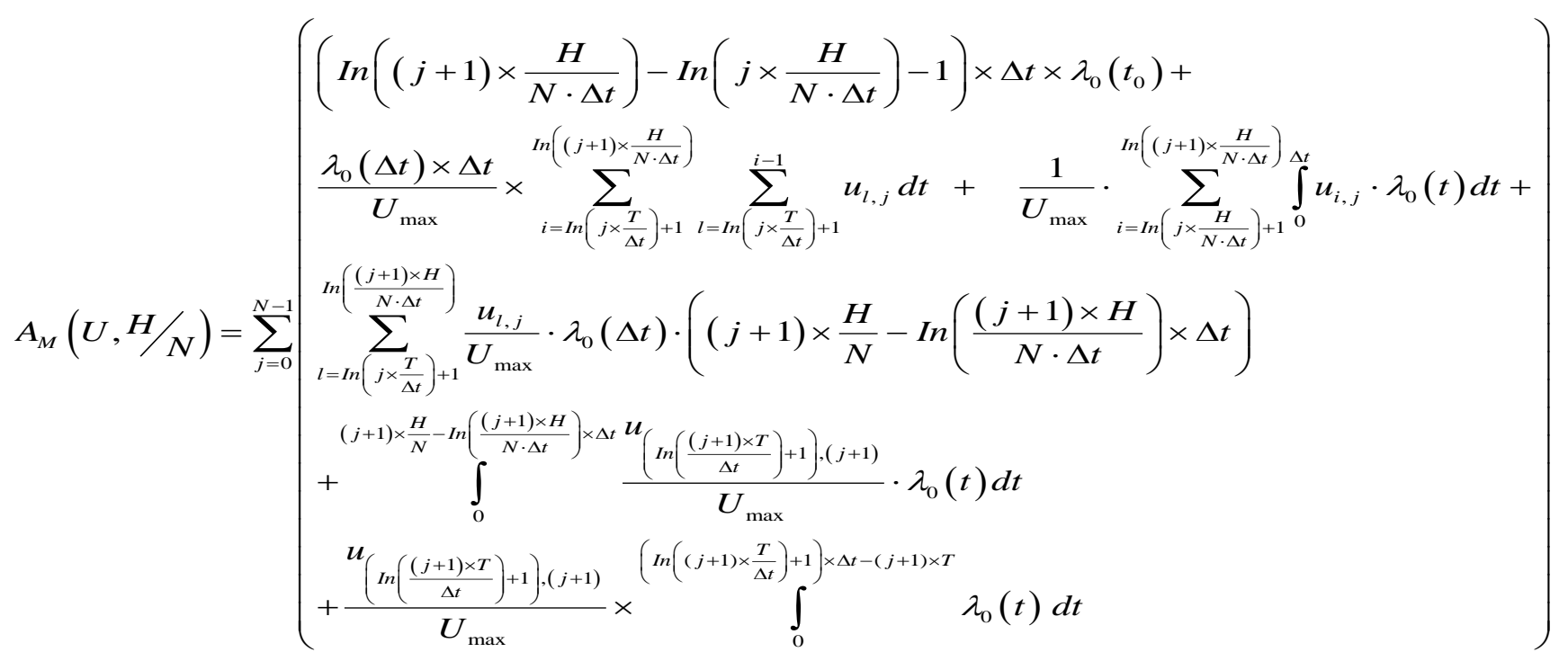

\section{IV.3. Numerical example:}

The following numerical example is considered to illustrate our approach. We use the same data for production, inventory and service level of the previous numerical example. The number $H$ of periods $\Delta t$ is equal to 24 , with $\Delta t=1$. The machine M1 has a degradation law characterized by a Weibull distribution. Recall that our contribution for maintenance is to study the influence of the variation of the production rate on the machine degradation that is new in the literature. Equation 24 shows the evolution of the machine failure rate according to its use (which is in our case the production rate for each period) respecting in the same time the continuity of the equipment reliability for a period to another. This equation has been validated in other papers. Concerning the weibull law, we have chosen as a numerical example where we have assumed that the degradation of the equipment follows the weibull law with parameters $\gamma=2$ et $\beta=100$ (with this two parameters, the degradation is linear $\gamma=2$ ). From this equation, we determined the average number of failure assuming that after each preventive maintenance action the equipment is on state "as good as new" and that maintenance action may be applied during the production as it can be at the end of the period.

The other data are as follows: $C_{p m}=500, C_{c m}=4500, \Delta t=1, \lambda_{0}=0.2, C_{p r l}=3 m u, C_{p r 2}=10 m u, U_{1}{ }^{m a U}=13, U_{2}{ }^{m a U}=13, \beta_{2}=0.93$, service level $\alpha=0.95, C s=5 m u$, initial inventory $S_{0}=20$ and the variance of demand $V_{d_{k}}=1.21$. 


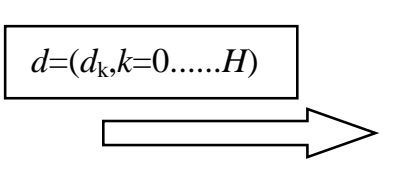

Optimization of returned production deadline: $\tau$ '

According to transported Delay $\tau$

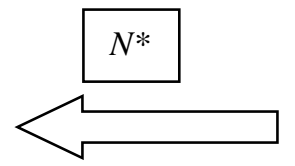

Total Maintenance

Cost $\xi_{M}\left(U_{1}, N\right)$

$U^{*}=\left(U_{1, k}, k=0 \ldots \ldots . H-1\right)$

Fig.12. Maintenance Optimization

Using the previous sections, an optimization procedure was implemented via the Numerical Algorithms for Constrained Global Optimization (NelderMead methods) with MATHEMATICA.

We obtain the optimal production plan $\left(U_{1, k}{ }^{*}\right)$ and the optimal maintenance period for different cases of subcontractor transportation delay $\tau$, which are exhibited respectively in figures 13-14-15.

\section{Case 1: Transportation Delay $\tau=0$}

- Optimal number $N^{*}$ of preventive maintenance actions

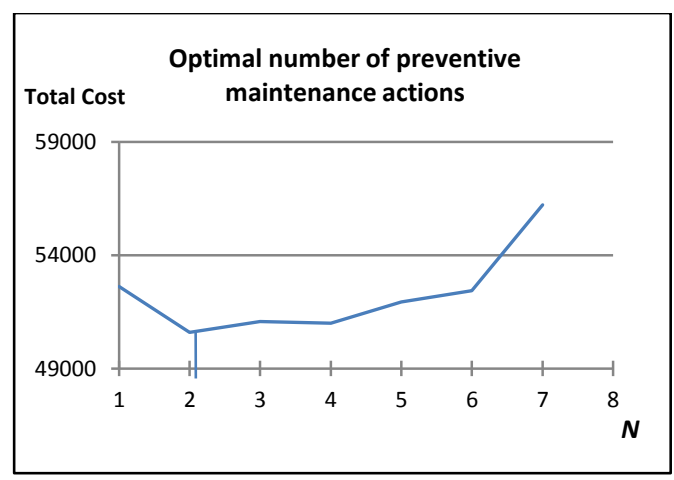

Fig.13. Total cost variation as a function of $N$

\section{Case 2: Transportation Delay $\tau=1$}

- $\quad$ Optimal number $N^{*}$ of preventive maintenance actions

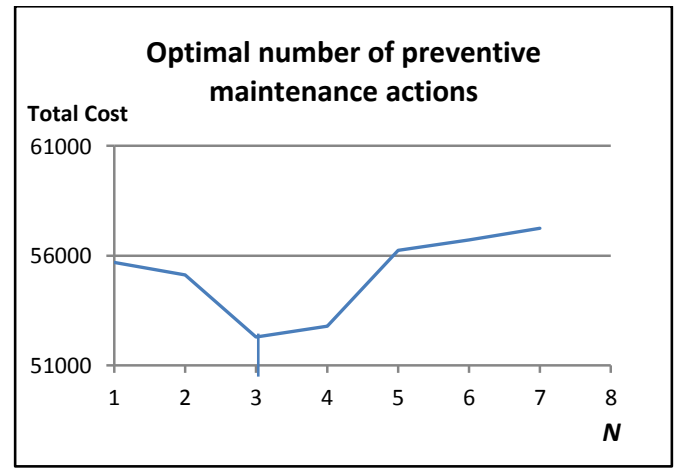

Fig.14. Total cost variation as a function of $N$

\section{Case 2: Transportation Delay $\tau=5$}

- Optimal number $N^{*}$ of preventive maintenance actions 


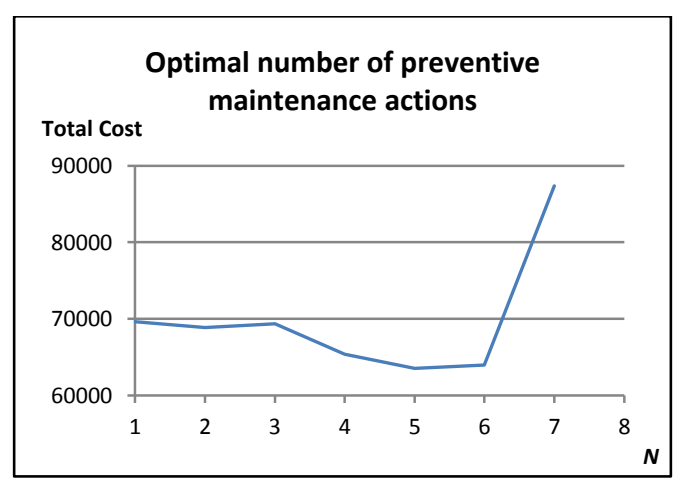

Fig.15. Total cost variation as a function of $N$

Figures 12-13-14 show the following results of the optimal total cost: The above figures illustrate the minimum total cost for different values of the number, $N$, of preventive maintenance actions to be performed. For each value of $\tau$, we calculate the economical production plan and the optimal number of preventive maintenance. We noted that for subcontractor transportation delay $\tau=0$, we obtained the optimal total cost equals to $50597.2 \mathrm{mu}$ with two preventive maintenance actions during the horizon $H=24$, this optimal total cost has become expensive for $\tau=1$ and equals to 52293.1mu with three preventive maintenance actions and more importantly expensive equals $63511.1 \mathrm{mu}$ with five preventive maintenance actions for $\tau=5$.

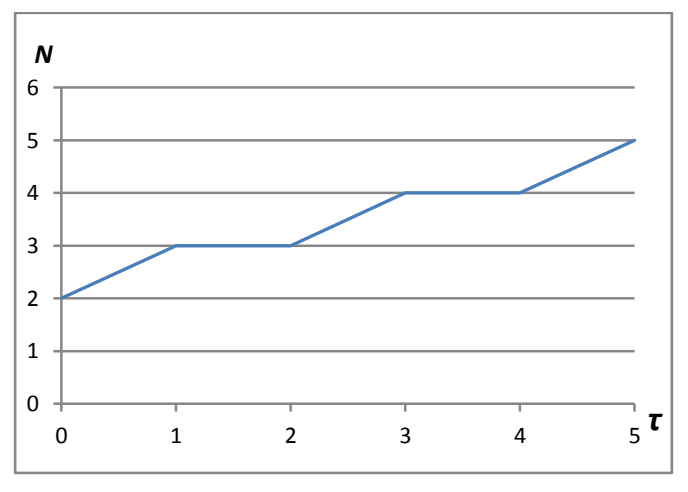

Fig.16. MP number variation as a function of $\tau$

Hence, from figure 15, we can see that the higher value of transportation delay $\tau$ corresponds to the higher of the optimal total cost and the optimal number of preventive maintenance actions. This can be explained by the fact that, as transportation delay $\tau$ increases, the principal machine produces more to meet the customers' demands, thus the machine will undergo more failures. According to the previous results presented through the variability of $\tau$, subcontractor transport delay is really impacted visibly.

\section{CONCLUSION}

This paper treats a constrained stochastic production and maintenance planning problem. In order to meet the all demand during the considered horizon, it then calls upon subcontracting. Under a given service level, we have formulated and solved the related stochastic production/inventory and maintenance problem.

The subcontractor is characterized by its transportation delay to principal stock, its availability, its maximum production capacity and its unit cost of production. The key of this study is to consider the influence of the subcontracting transportation delay on the production, inventory and maintenance context.

Firstly, initial case where we consider the production system without returned products; we formulated and solved a linearquadratic stochastic production problem to obtain a preliminary production plan taking into account the subcontracting transportation delay. Using the HMMS model, the preliminary production plan includes the production and inventory costs under a given service level. This plan defines the production rates for the main production system and for the subcontractor's machine during each period over the production horizon. Thereafter, we evaluate the subcontracting transportation delay influence on the production plan.

Secondly, we consider the production system taking into account the products returned by the customers. In this part we optimize the deadline authorized for the products return by express a relationship between the subcontractor's transportation 
delay and the returned products deadline in order to minimize the total cost. In the last part, we treated the influence of subcontractors transportation delay in the maintenance policy in order to obtain the optimal number of preventive maintenance minimizing the total production, inventory and maintenance cost.

For future research, we will consider a more complex system with a transportation cost of the sub-contractor. We will take into account also the cost of order execution. Concerning the maintenance strategy, we will consider new hypotheses: the corrective and preventive times are not negligible. In this case we deal with new policy to recover the quantity lost during the maintenance time.

Another perspective research, we consider the aspect of leasing in our problem, the idea is to switch between a subcontracting machine and leased machines in order to minimize the production, inventory and maintenance Cost.

\section{REFERENCES}

[1] Amesse, F., Dragoste, L., Nollet, J. and Ponce, S., 2001. "Issues on partnering: evidences from subcontracting in aeronautics". Technovation, 21 (9), 559-569.

[2] Andersen, P.H., 1999.” Organizing international technological collaboration in subcontractor relationships: an investigation of the knowledge-stickiness problem". Research Policy, 28 (6), 625-642.

[3] Ayed S., Dellagi S., Rezg N., 2012." Joint optimisation of maintenance and production policies considering random demand and variable production rate". International Journal of Production Research, vol. 50, Issue 23, p 6870-6885.

[4] Aghzzaf, E. and Najid, N. (2008). "Integrated production and preventive maintenance in production systems subject to random failures". European journal of operational research, 178:3382-3392.

[5] Bertrand, J.W.M. and Sridharan, V., 2001. "A study of simple rules for subcontracting in make-to-order manufacturing". European Journal of Operational Research, 128 (3), 509-531.

[6] Bertesekas, D.P, 1995. "Dynamic Programming and Optimal Control". Athena Scientific, vol. II.

[7] Dellagi, S., Rezg, N. and Uie, U., 2007. "Preventive maintenance of manufacturing systems under environmental constraints". International Journal of Production Research, 45 (5), 1233.

[8] Dahane M, Clementz C, Rezg N, 2010," Effects of extension of subcontracting on a production system in a joint maintenance and production context", Computers \& Industrial Engineering, 58(1):88-96, DOI:10.1016/j.cie.2009.08.007.

[9] Hajej Z., Dellagi S., Rezg N., 2011. "Optimal integrated maintenance/production policy for randomly failing systems with variable failure rate" International Journal of Production Research, vol. 49, Issue 19, pp 5695-5712.

[10] Hajej Z., Dellagi S., and Rezg N., 2009. "An optimal production/maintenance planning under stochastic random demand, service level and failure rate". IEEE explore. Issue 22-25 Aug: 292-297. India.

[11] Hajej Z., Dellagi S., and Rezg N.,2012 "Joint optimisation of maintenance and production policies with subcontracting and product returns", Journal of Intelligent Manufacturing, doi 10.1007/s10845-012-0707-9

[12] Hax, A. and Candea, D., 1984. Production and Inventory Management. Prentice Hall, Englewood Cliffs.

[13] Holt, C., Modigliani, C., Muth, J. F., and Simon, H. A. (1960). Planning Production Inventories And Workforce. Prentice Hall.

[14] Richard Y.K. Fung, Tsiushuang Chen, 2005 "multiagent supply chain planning and coordination architecture", International Journal of Advanced Manufacturing Technology, vol 25, Issue 7, pp 811-819.

[15] Turki S. ; Hajej, Z. ; Rezg N., 2012, "Impact of delivery time on optimal production/delivery/maintenance planning", IEEE International Conference on Automation Science and Engineering (CASE), 2012, pp335 - 340, Seoul.

[16] Silva Filho, O.S. and Cezarino, W., 2004. An optimal production policy applied to a flow-shop manufacturing system. Brazilian Journal of Operations and Production Management, 1 (1), 73-92.

[17] Singhal, J. and Singhal, K. (1996). Alternate approach to solving the holt and al. model and to performing sensitivity analysis. European Journal of of Operationnal Research, 91:89-98.

\section{Annex}

It's assumed that the demand variable has its first and second statistic moments perfectly known for each period $k$, that is, $E\left\{d_{k}\right\}=\hat{d}_{k}$ and $\operatorname{Var}_{d_{k}}=\sigma_{d}^{2}$ (standard deviation) for each $k$.

The inventory variable $S_{k}$ is statistically described by its mean; $E\left\{S_{k}\right\}=\hat{S}_{k}$ and its variance $\operatorname{Var}_{S_{k}}$,

$\operatorname{Var}_{S_{k}}=E\left\{\left(S_{k}-\hat{S}_{k}\right)^{2}\right\}$

$U_{k}$ being constant for each interval $\Delta t$, we have $\hat{U}_{k}=U_{k}$ and $\operatorname{Var} U_{k}=0$.

$U_{k}$ is essentially deterministic, since it does not dependent on the random variables $d_{k}$ and $\hat{S}_{k}$.

Thus $\hat{U}_{k}=U_{k}$ and $\operatorname{Var}_{U_{k}}=0$

The balance equation (2) can be reformulated this way:

$$
\hat{S}_{k+1}=\hat{S}_{k}+U_{1, k}+\beta_{2} \cdot U_{2, k-\tau}-\hat{d}_{k}
$$

If we make the difference between equations (2) and (26) we obtain:

$$
S_{k+1}-\hat{S}_{k+1}=S_{k}-\hat{S}_{k}-\left(d_{k}-\hat{d}_{k}\right)
$$




$$
\begin{gathered}
\Rightarrow\left(S_{k+1}-\hat{S}_{k+1}\right)^{2}=\left(\left(S_{k}-\hat{S}_{k}\right)-\left(d_{k}-\hat{d}_{k}\right)\right)^{2} \\
\Rightarrow E\left\{\left(S_{k+1}-\hat{S}_{k+1}\right)^{2}\right\}=E\left\{\left(\left(S_{k}-\hat{S}_{k}\right)-\left(d_{k}-\hat{d}_{k}\right)\right)^{2}\right\} \\
\Rightarrow E\left\{\left(S_{k+1}-\hat{S}_{k+1}\right)^{2}\right\}=E\left\{\left(S_{k}-\hat{S}_{k}\right)^{2}\right\}+E\left\{\left(d_{k}-\hat{d}_{k}\right)^{2}\right\}-2 E\left\{\left(S_{k}-\hat{S}_{k}\right)\left(d_{k}-\hat{d}_{k}\right)\right\}
\end{gathered}
$$

Since $S_{k}$ and $d_{k}$ are independent random variables, we can deduce that:

$E\left\{\left(S_{k}-\hat{S}_{k}\right)\left(d_{k}-\hat{d}_{k}\right)\right\}=E\left\{\left(S_{k}-\hat{S}_{k}\right)\right\} E\left\{\left(d_{k}-\hat{d}_{k}\right)\right\}$

Hence:

$E\left\{\left(S_{k}-\hat{S}_{k}\right)\right\}=E\left\{S_{k}\right\}-E\left\{\hat{S}_{k}\right\}=0$ and $E\left\{\left(d_{k}-\hat{d}_{k}\right)\right\}=E\left\{d_{k}\right\}-E\left\{\hat{d}_{k}\right\}=0$

Therefore

$$
\begin{gathered}
E\left\{\left(S_{k+1}-\hat{S}_{k+1}\right)^{2}\right\}=E\left\{\left(S_{k}-\hat{S}_{k}\right)^{2}\right\}+E\left\{\left(d_{k}-\hat{d}_{k}\right)^{2}\right\} \\
\Rightarrow\left(\sigma_{S_{k+1}}\right)^{2}=\left(\sigma_{S_{k}}\right)^{2}+\left(\sigma_{d_{k}}\right)^{2}
\end{gathered}
$$

If we assume that $\sigma_{S_{0}}=0$ (for $k=0$ ) and that $\sigma_{d_{k}}$ is constant and equal to $\sigma_{d}$ for all the periods, we can deduce that:

$$
\left(\sigma_{S_{k}}\right)^{2}=k\left(\sigma_{d_{k}}\right)^{2}
$$

Since $\operatorname{Var}_{S_{k}}=E\left\{\left(S_{k}-\hat{S}_{k}\right)^{2}\right\}=E\left\{S_{k}^{2}\right\}-\hat{S}_{k}^{2}$ and $\operatorname{Var}_{S_{k}}=\left(\sigma_{S_{k}}\right)^{2}=k\left(\sigma_{d_{k}}\right)^{2}$

We can write $E\left\{S_{k}^{2}\right\}-\hat{S}_{k}^{2}=k\left(\sigma_{d}\right)^{2}$

$$
E\left\{S_{k}^{2}\right\}=k\left(\sigma_{d}\right)^{2}+\hat{S}_{k}^{2}
$$

Substituting (28) in the expression (6) of the expected cost we obtain:

$$
\begin{aligned}
& F(u)=C_{s} \cdot \hat{S}_{H}^{2}+\sum_{k=0}^{H-1}\left[C_{s} \cdot \hat{S}_{k}^{2}+C_{p r 1} \cdot U_{1, k}^{2}+C_{p r 2} \cdot \beta_{2} \cdot U_{2, k}^{2}\right]+C_{s} \cdot\left(\sigma_{d}\right)^{2} \cdot \sum_{k=0}^{H-1} k \\
& \Rightarrow F(u)=C_{s} \cdot \hat{S}_{H}^{2}+\sum_{k=0}^{H-1}\left[C_{s} \cdot \hat{S}_{k}^{2}+C_{p r 1} \cdot U_{1, k}^{2}+C_{p r 2} \cdot \beta_{2} \cdot U_{2, k}^{2}\right]+C_{s} \cdot\left(\sigma_{d}\right)^{2} \cdot \frac{H(H+1)}{2}
\end{aligned}
$$

